University of Louisville

ThinkIR: The University of Louisville's Institutional Repository

Electronic Theses and Dissertations

$12-2020$

\title{
The many facets of trauma - high need index school principals' perspectives of trauma-informed care.
}

Nicole Michelle Fields

University of Louisville

Follow this and additional works at: https://ir.library.louisville.edu/etd

Part of the Educational Leadership Commons

\section{Recommended Citation}

Fields, Nicole Michelle, "The many facets of trauma - high need index school principals' perspectives of trauma-informed care." (2020). Electronic Theses and Dissertations. Paper 3550.

https://doi.org/10.18297/etd/3550

This Doctoral Dissertation is brought to you for free and open access by ThinkIR: The University of Louisville's Institutional Repository. It has been accepted for inclusion in Electronic Theses and Dissertations by an authorized administrator of ThinkIR: The University of Louisville's Institutional Repository. This title appears here courtesy of the author, who has retained all other copyrights. For more information, please contact thinkir@louisville.edu. 


\title{
THE MANY FACETS OF TRAUMA - HIGH NEED INDEX SCHOOL PRINCIPALS' PERSPECTIVES ON TRAUMA-INFORMED CARE
}

\author{
By \\ Nicole Michelle Fields \\ University of Louisville \\ B.S., University of Louisville, 2004 \\ M.A., Webster University, 2010 \\ M.Ed., Spalding University, 2014
}

\begin{abstract}
A Dissertation
Submitted to the Faculty of the

College of Education and Human Development of the University of Louisville In Partial Fulfillment of the Requirements

For the Degree of

Doctor of Education

In Educational Leadership and Organizational Development

Department of Educational Leadership and Organizational Development

University of Louisville

Louisville, Kentucky
\end{abstract}

December 2020 
Copyright 2020 by Nicole Michelle Fields

All rights reserved 

THE MANY FACETS OF TRAUMA - HIGH NEEDS INDEX SCHOOL PRINCIPALS' PERSPECTIVES ON TRAUMA-INFORMED CARE

By

Nicole M. Fields

University of Louisville

B.S., University of Louisville, 2004

M.A., Webster University, 2010

M.Ed., Spalding University, 2014

A Dissertation Approved on

November 18, 2020

By the following Dissertation Committee:

Dr. Mary Brydon-Miller, Chair

Dr. Detra D. Johnson

Dr. Ishwanzya Rivers

Dr. Harrie Buecker 


\title{
DEDICATION
}

\author{
My three heartbeats \\ Noah, Nolan, and Taylor Fields
}

\author{
My rock \\ Tyrone Fields \\ We are TEAM FIELDS
}

\author{
My earthly angel \\ Charlye Mae Trowell
}

The three heavenly angels

Dorothy Hatchett, James Trowell Sr., and Jesse Hatchett 


\section{ACKNOWLEDGEMENTS}

God is within her; she will not fall. Psalms 46:5

I would like to thank God for all of his grace and mercy through this process. I thank you for the opportunity to use the gift you have provided to help enhance how we address trauma within education. Thank you for being YOU. Thank you for completing this work with me. For this, I give you praise.

Tyrone, thank you for being my rock. You are the best husband in the world. You are an amazing father to our children, and I am forever grateful that you love me. I could not have completed this journey without you. I appreciate your endless support and being my biggest cheerleader. Noah, Nolan, and Taylor, I love you past the moon. Thank you for the many hugs and motivational pep talks. I needed every single one. Always remember, we are Team Fields, and failure is not an option. Always remember to keep moving. To my amazing parents, Wayne and Lisa Hatchett, I thank you for teaching me the love of education and having a great work ethic. It is by your examples that I am who I am today.

I want to extend my gratitude to my dissertation committee for your belief in me and this dissertation study. My committee chair, Dr. Mary Brydon-Miller, thank you for your unwavering support and for keeping myself and my family held to the light. You have three future students coming your way. Thank you, Dr. Johnson, for always pushing me, inspiring me, and showing me the sky is the limit. Dr. Rivers, thank you for being a listening ear, helping me refocus and dig deeper into my research. Dr. Buecker, for always having a positive word of encouragement and cheering me along this journey.

A special thank you to my cohort, Block 20. Dr. Rajwinder Kauur, Manuel Garr, Rob 
Fulk, Carmen Bellefant, Kendra Nolan, Whitney Taylor, Adrian Graham, Jodie Zeller, and Scott U'Sellis, I love you all and glad our paths have crossed. A special hug to Manuel (Minster/Deacon), Raj (Writing Cousin), and Rob (Lead Man) for being my accountability partners on this journey.

I would like to thank other people who have been integral in this research and my life. I want to acknowledge my sisters LaKeesha (Eric) Turner and Tiffany (Lai'Chan) Hatchett for believing in your big sister. I wish to recognize all of my family for your support during my journey. I want to acknowledge the 33 Chronicles of Perseverance and Delta Sigma Theta Sorority, Incorporated sorors for the sisterhood and support. I also want to thank Dr. Deborah Powers, Dr. Marco Munoz, Dr. Carla Kent, Dr. Damien Sweeney, Scott Mitchell, the Dance Moms, Black Girl Magic, Deborah Barnes-Byers, Kennisha Fisher, Lisa Murray, and all of my friends who prayed for me. Each of your prayers and love were truly felt. Thank you all from the bottom of my heart for your support. 


\begin{abstract}
THE MANY FACETS OF TRAUMA - HIGH NEEDS INDEX SCHOOL PRINCIPALS' PERSPECTIVES ON TRAUMA-INFORMED CARE
\end{abstract}

\author{
Nicole M. Fields
}

November 18, 2020

This qualitative phenomenological study attempts to add to the literature by shedding light on the best practices for fostering and applying effective trauma-informed care (TIC) in schools and the educational practices and policies through human experience elements. Creating trauma-sensitive, safe, and supportive schools requires a new discernment among principals. It also requires holistic changes to transform school, culture, build supporting infrastructure, and alter curriculum content and intervention (McInerney \& McKlindon, 2014). TIC refers to treating the whole person mentally, socially, emotionally, and physically. This study interview 14 principals' perspectives in a large urban school district to discover what practices, procedures, and policies were implemented to address student traumas and TIC within their buildings. TIC considers past trauma and the resulting coping mechanisms when attempting to understand behaviors and treat the students. By not addressing this matter, more children will more than likely continue to walk into schools in which educators may mistake trauma for misbehavior, specifically for students of color (Mader, 2019). 


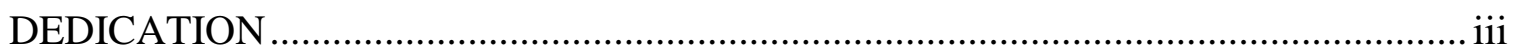

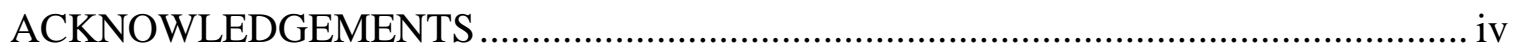

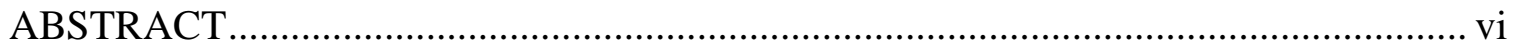

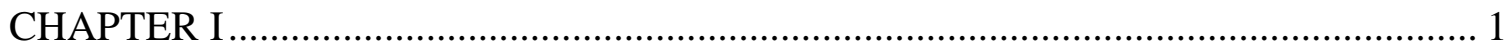

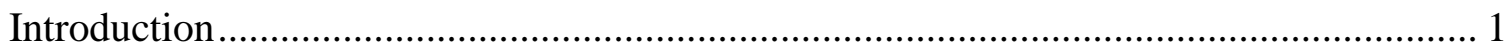

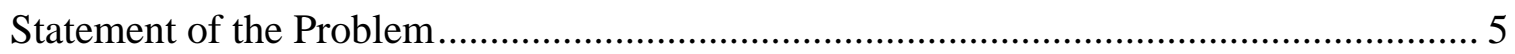

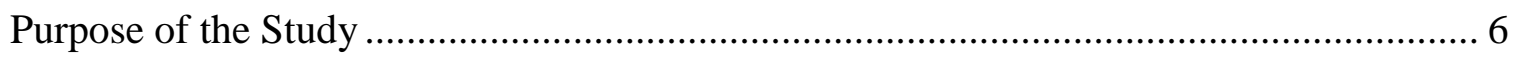

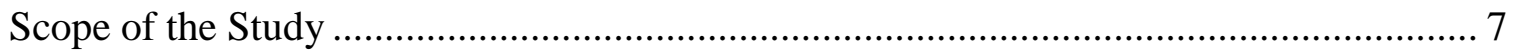

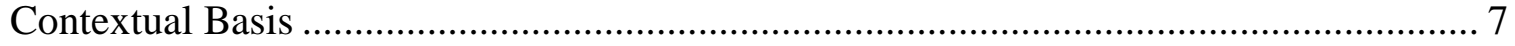

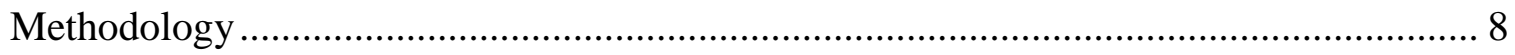

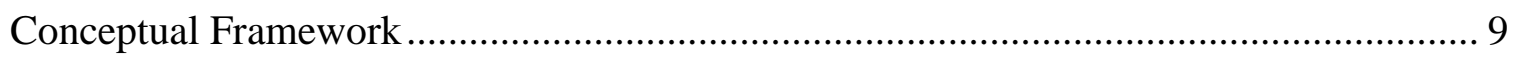

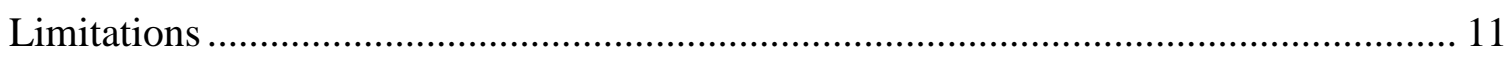

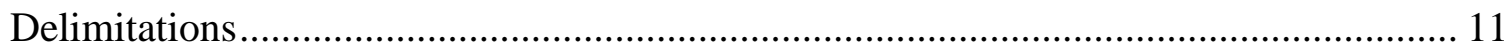

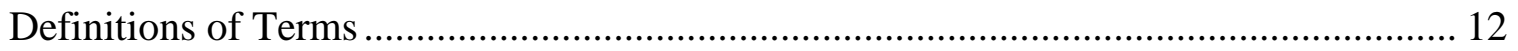

Summary and Organization of Forthcoming Chapters ……………………………....... 13

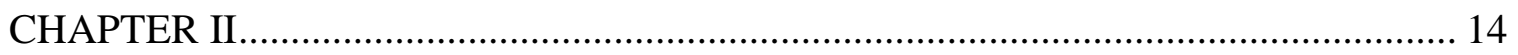

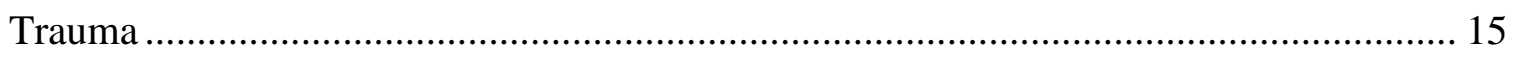

Adverse Childhood Experiences (ACEs)................................................................ 17

Impacts of Trauma

Student Behavior ……………………......................................................... 20

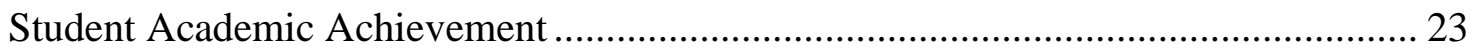

Student Social-Emotional Learning (SEL) ……………..................................... 25

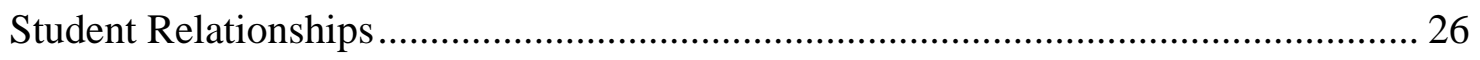

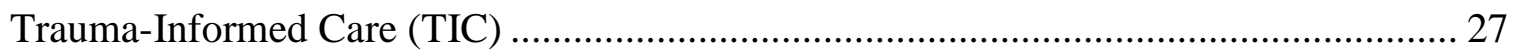

Trauma-Informed Policies .................................................................................... 30

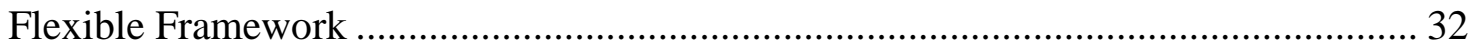

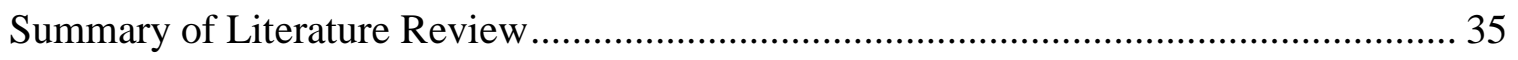

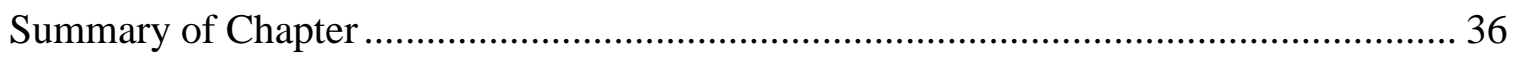

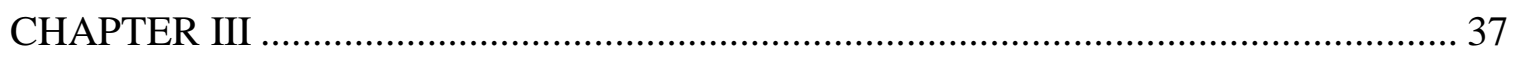

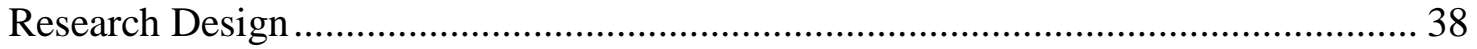




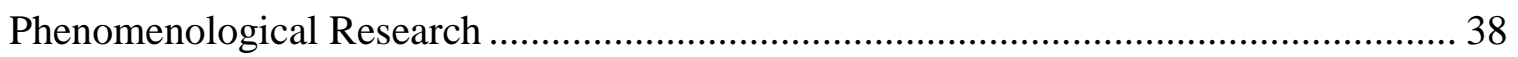

The Rationale for Using Phenomenological Research Design ......................................... 38

Conceptual Framework ………………………………...................................... 39

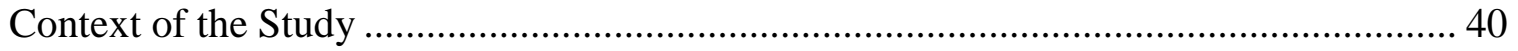

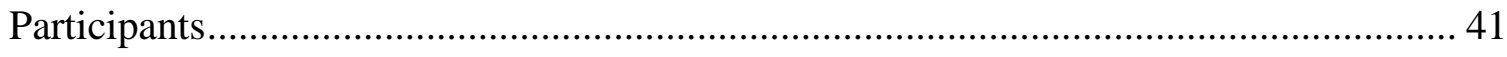

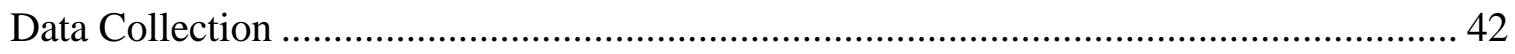

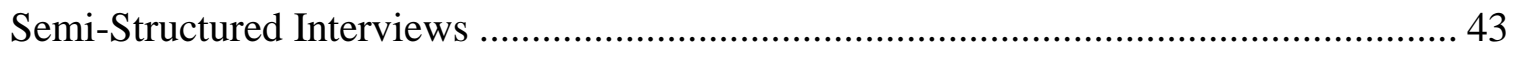

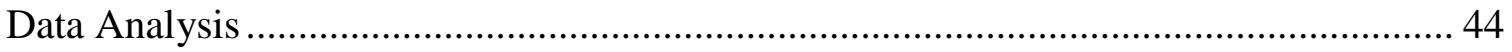

Qualitative Validity and Ethical Consideration .............................................................. 45

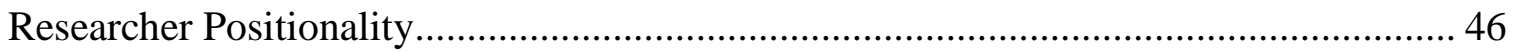

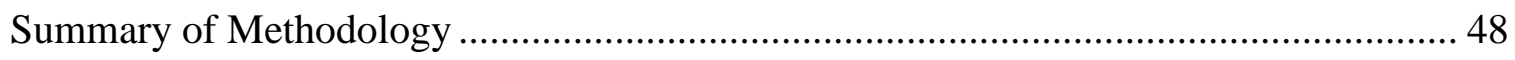

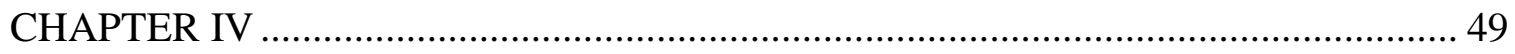

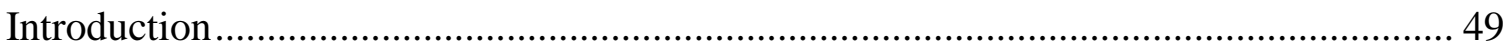

Trauma-Sensitive School Checklist Questionnaire …………………………………..... 56

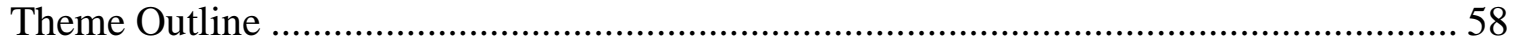

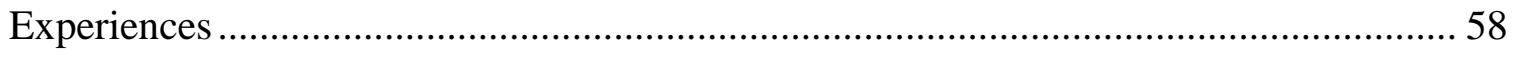

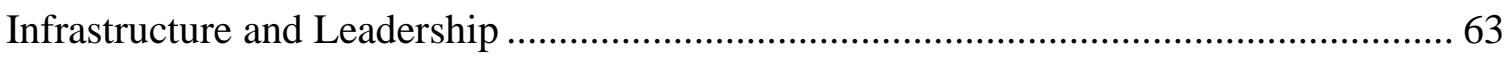

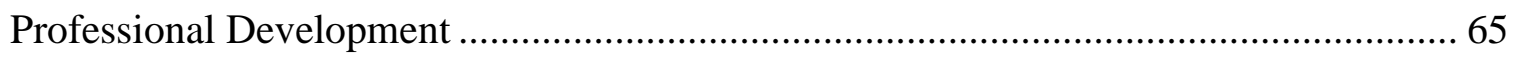

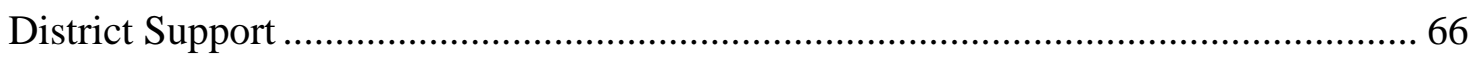

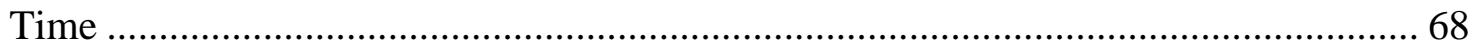

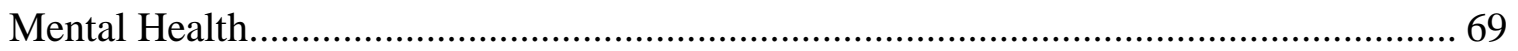

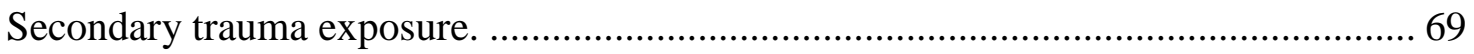

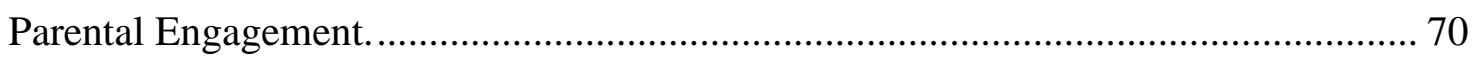

Classroom-Based Academic Strategies …………………............................................. 73

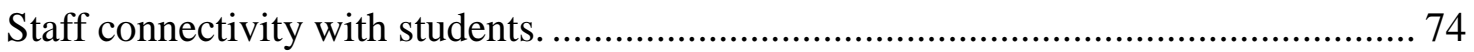

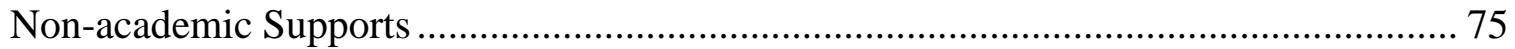

Policies, Procedures, and Protocols ................................................................................ 77

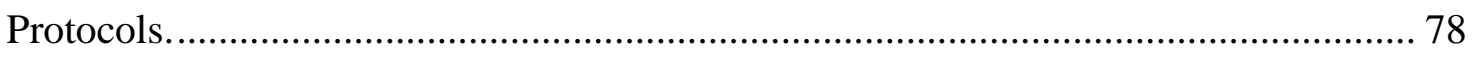

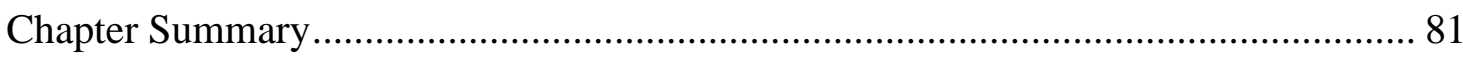

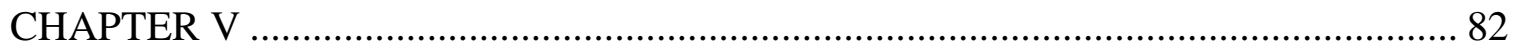

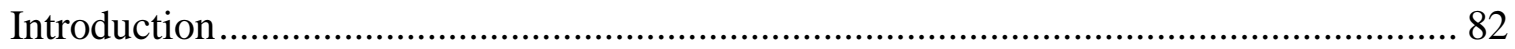

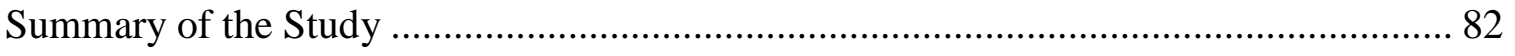




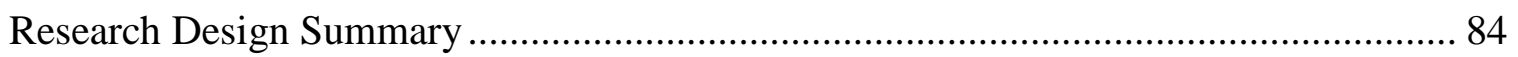

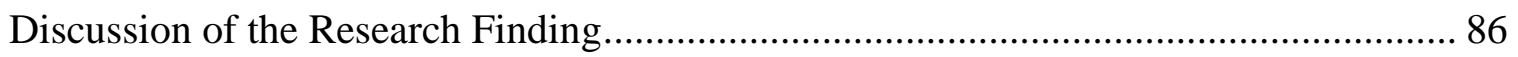

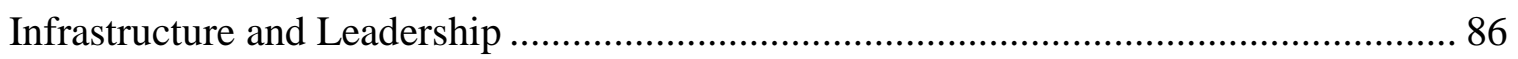

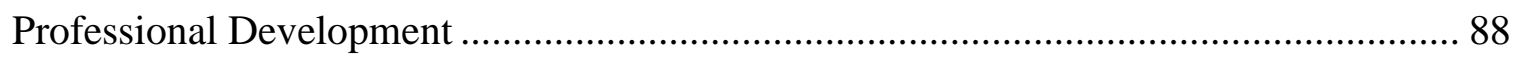

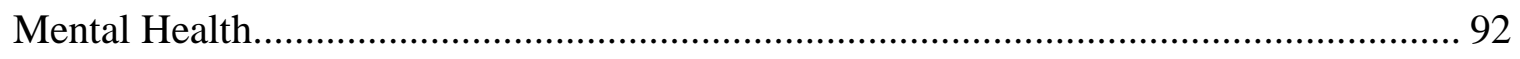

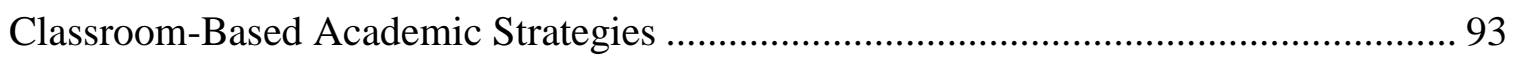

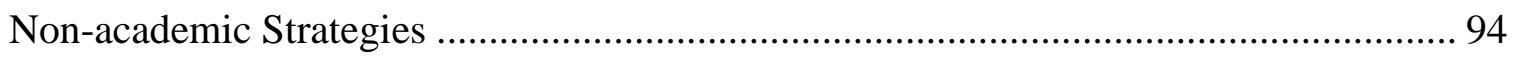

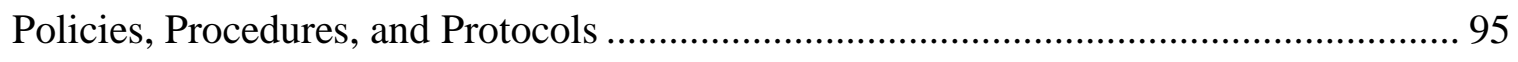

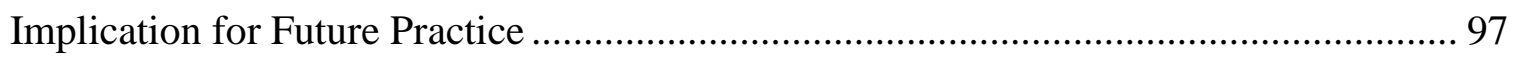

Implication for Future Policy ................................................................................... 98

Recommendations for Future Research .................................................................. 99

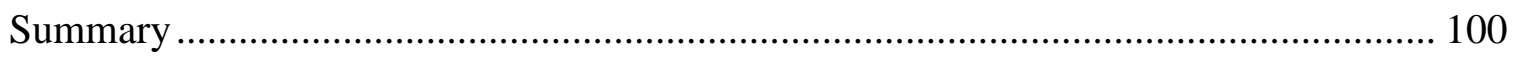

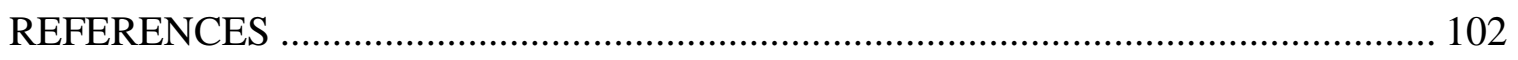

Appendix A - Trauma-Sensitive Checklist Survey ...................................................... 110

Appendix B - Proposed Timeline and Budget ……………........................................ 112

Appendix C - Informed Consent ............................................................................ 113

Appendix D - Informed Protocol - Principals ……………………………………... 117

Appendix E - Interview Protocol - Social-Emotional Director ....................................... 119

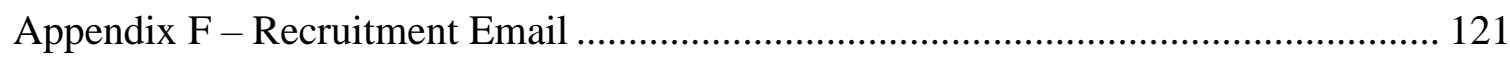

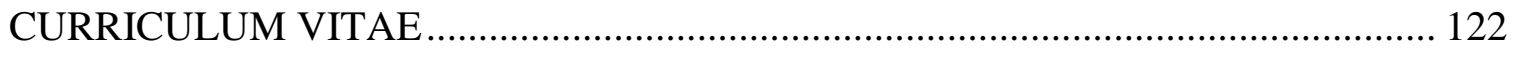




\section{CHAPTER I}

\section{INTRODUCTION}

Globally, it is estimated that up to 1 billion children aged 2-17 years have experienced physical, sexual, or emotional violence or neglect in the past year (Hillis, Mercy, Amobi, \& Kress, 2016). Students across the country are experiencing universal trauma with the coronavirus (COVID-19) pandemic. Traditional brick-and-mortar schools have stopped; families share food insecurities; non-essentials jobs have been forced to close or stop, and COVID-19 is spreading like wildfire. These events are examples of trauma. Students are enduring trauma in many forms. One in every ten Kentucky children has already had three or more traumatic experiences before the age of nine- including family divorce, domestic violence, or drug abuse - a rate tied for highest in the country (Keening, 2013). Presently, Kentucky students are experiencing the universal trauma of the pandemic and, locally, racial unrest from the murder of Breonna Taylor, an African-American woman who was murdered in her home by local police in Louisville. These events have contributed to adverse childhood experiences.

The Center for Disease Control and Prevention (CDC) calls these experiences Adverse Childhood Experiences (ACEs). ACEs are commonly described as abuse, neglect, and other potentially traumatic experiences for people under the age of 18. ACEs affects many students over time. Osher (2018) found students exposed to three or more ACEs were two and a half times more likely to fail a grade, score lower on standardized achievement tests, have more receptive and expressive language difficulties, or be 
suspended or expelled, and referred more to special education services (Rossen \& Hull, 2013). Principals can address student ACEs by employing compassionate and creative responses and strategies to help students and their families develop healthy habits to build resiliency for successful student learning (Rossen \& Hull, 2013). Principals must have a new discernment to create trauma-sensitive, supportive, and safe schools for all students experiencing trauma.

Futhermore, Perry (2009) argued that trauma, maltreatment, and neglect of a student might affect students' ability to regulate their social, emotional, and behavioral functions. Steinberg, Colasanti, Huckman, and Popazoglou (2011) indicate that students who experienced trauma bring these experiences into the educational setting. Trauma often diminishes students' difficulty with concentration, memory, organization, language, impulsive behaviors, lower grade-point average, and overwhelming feelings of frustration (National Child Traumatic Stress Network Schools Committee, 2008; O'Grady, 2017). Students impacted by trauma tend to react rather than plan thoughtfully and are driven by the need for survival (Rossen \& Hull, 2013). To date, one out of every four students attending school is exposed to a traumatic event that can affect learning and behavior (National Child Traumatic Stress Network Schools Committee, 2008).

The Center for Substance Abuse Treatment (2014) states that trauma can affect people of every race, ethnicity, age, sexual orientation, gender, psychosocial background, and geographic region. Soma and Allen (2017) emphasized, "trauma is not just the incident but rather how the person experiences what happened or what is happening" (p.27). According to Rossen and Hull (2013), students who have experienced trauma might struggle with a multitude of competencies that influence school performance and 
engagement, including the following: concentrating in class, staying attentive, managing behavior, negotiating relationships, regulating emotions, executing functions, accomplishing goals, planning and believing in a positive future, and faith in having the potential to work toward one. Students' manifest symptoms affected by trauma have been widely documented, including self-isolation, aggression, and attentional deficit, and hyperactivity, that produces individual and school-wide difficulties (Cook et al., 2017; Iachini, Petiwala, \& DeHart, 2016; Oehlberg, 2008). More children continue to walk into schools that mistake trauma for misbehavior by not addressing this matter, specifically for students of color (Mader, 2019). In his study, Johnson (2018) found that many of these children's behaviors were treated as a policing matter rather than a case of mental health and trauma. Unfortunately, these students become more likely to enter the schoolto-prison pipeline. Principals should avoid punitive punishments that negatively affect students who experience, generate more negative behaviors, increase school suspensions, and increase entering prison (Dutil, 2020). Markedly Chak (2010) stated that traumainformed professionals could better recognize and understand the child's trauma response behaviors and better support the child in ways that create healing. An increased interest in trauma-informed care or trauma-sensitive schools in education has emerged in recent years.

Trauma-Informed Care (TIC) refers to helping the whole person while considering past trauma and the resulting coping mechanisms when attempting to understand behaviors and treat the students (Substance Abuse and Mental Health Services Administration, 2014). To treat the whole person means addressing the trauma that impacts that person mentally, socially, emotionally, spiritually, and physically. In 
discussing TIC, Whitaker et al. (2019) argue TIC practices may have more significant effects if they involved the entire organization, including supervisors (principals), and change the way individuals in organizations relate to each other. Notably, Ridgard et al. (2015) stated, "students from racial/ethnic minority and lower socioeconomic backgrounds disproportionally experience some potentially traumatic events, provision of trauma-informed care in schools may minimize disparities in academic, behavioral, and psychosocial outcomes related to the experience of trauma" (p.14). Ridgard et al. (2015) acknowledged by using a trauma-informed approach in schools virtually ensures that the negative impact of trauma is recognized and that the needs of students who have experienced trauma are addressed. It is crucial to obtain the principal's perspectives to expand school improvement plans in academic and non-academic capacities. Principals lead the instrumentation of programs and initiatives within their schools. Principals must have a clear understanding of Trauma-Informed Care to become the change agents students need to address trauma. Therefore, school principals need to recognize signs of trauma to implement practices, procedures, and policies to ensure trauma is not handled in a policing manner.

However, few studies to date have examined principals' perspectives of student trauma and its implications for students and schools. Numerous studies have examined the impact of Trauma-Informed Care from the teacher's perspectives (Anderson, Blitz, \& Saastamoinen, 2015; Baweja et al., 2016; Green, Xuan, Kwong, Holt, \& Comer, 2016; Mendelson, Tandon, O'Brennan, Leaf, \& Ialongo, 2015; Osagiede et al., 2018; Perry \& Daniels, 2016; Whitaker et al., 2019). According to Walkely and Cox (2013), the importance of "commitment to adopting a trauma-informed approach will require the full 
support and commitment of the leadership at each school, starting with the principal and co-principal" (p.125). Principals serve as educational leaders in ensuring educational practices, student achievement, instructional procedures, and the development of building policies facilitated in school when encountering traumatized students. While it is true that teachers are often the first line of defense when students experience trauma, the teacher seeks guidance from building leaders on how to address the barriers to students learning

effectively. On the positive side, McInerny and McKlindon (2014) remind us that schools have an essential role in providing stability, a safe space for children, and caring relationships with adults. Also, schools serve as support services that can adapt curricula and behavioral interventions to meet better students' educational needs who have experienced trauma. As a result, the educational system serves as a crucial influence on students' development.

\section{Statement of the Problem}

The National Child Traumatic Stress Network Schools Committee (2008) suggested eliminating disparities in trauma services requires culturally active involvement across service sectors, communities, organizations, neighborhoods, families, and individuals to reduce barriers, overcome stigma, address social adversities, strengthen families, and encourage positive ethnic identity. Perry and Daniels (2016) support the notion that school systems serving children exposed to trauma must deal with their unique challenges to achieve academic success. The principal must create strategies to alter how their school understands and responds to youth's needs exposed to trauma. More students arrive at school, bringing with them traumatic experiences that can significantly affect how they engage in the school environment. 


\section{Purpose of the Study}

The purpose of my study was to examine principals' perspectives of trauma, how they address students experiencing trauma, and if and how they utilize Trauma-Informed Care to remove barriers to students learning in high Need Index (NI) schools. High NI schools provide more student diversity and are more likely to see higher volumes of students who have experienced or are currently experiencing trauma. Furthermore, Moon et al. (2017) argue that it is imperative to assess school administrators' perceptions of and attitudes toward mental health promotion in schools. More students have arrived at school, having experienced trauma that can significantly affect how they engage in the school environment. I sought to answer the following research questions:

1. What understandings do high Need Index school principals have concerning student trauma?

2. What are the high Need Index principals' perceptions of potential strategies that could be implemented to address student trauma within existing schoolwide practices?

3. What are the high Need Index principals' perceptions of whether TraumaInformed Care practices achieve their intended purpose, and what do they recommend for the future?

Data collected from this study will provide a wealth of information for principals to examine as potential strategies to address student trauma within existing schoolwide practices. Finally, this work brings communication to a broader audience of educators in school districts working in high Needs Index schools in large urban school districts to 
create equitable practices, procedures, and policies for Trauma-Informed Care for all schools and students.

\section{Scope of the Study}

This study was conducted in Jefferson County Public Schools (JCPS). School principals were selected based on school Need Index scores (NI). The schools were selected based on NI scores of $42.0 \%$ or higher. The NI calculation is formulated within the Diversity and Equity Department within JCPS. NI scores are constructed on the percentage of Exceptional Child Education students; the percentage of English Language Learners; the schools' mobility index rate, and the schools' free and reduced-price lunch rates. All JCPS principals with high NI, over $42.0 \%$, and at least two years of experience as a principal were allowed to participate in the study.

\section{Contextual Basis}

It is essential to recognize a timeline of events that may have impacted this study. According to the Centers for Disease Control and Prevention, in late 2019, COVID-19, or coronavirus, a deadly respiratory disease, spread around the country, causing a pandemic. In March 2020, Jefferson County Public Schools cease traditional brick-and-mortar instruction due to the coronavirus's spread. The district launched its first online and virtual learning platform called Non-Traditional Instruction or NTI 1.0. The district had a three-week window to create this online platform. This sizeable urban district experiences a digital divide due to the students and families not having adequate or needed resources 
to participate in this platform. Although the district supplied 30,000 Chromebooks, many families were forced to use paper packets provided by the schools and forego virtual instruction.

As principals were adjusting to distant learning, Louisville's city would begin to receive worldwide exposure following the murder of Breonna Taylor in March 2020. Ms. Taylor was a 26-year-old emergency technician shot and killed in her home with Louisville Metro Police Department Officers. These officers were not arrested or charged with her murder. The city experience an uprising due to racial unrest and social injustice. While a pandemic and racial unrest are occurring, the pandemic of homelessness, pandemic food insecurities, and the pandemic of education inequities already existed and were aspirated during the COVID-19 and Breonna Taylor murder.

In June 2020, the principals wrapped up a complex and complicated school year experiencing unforeseen events. The interviews for this research began in June 2020. Principals were starting to plan for the following school year, uncertain if it would be virtual learning or a traditional brick-and-mortar school.

\section{Methodology}

I utilized a narrative phenomenological research design. A phenomenological study uncovers meaning while articulating the lived experience of the participants (Creswell, 2014). Phenomenology focuses on describing what all participants have in common. The research's primary purpose is to reduce individual experiences with a phenomenon to describe the universal essence (Bloomber \& Volpe, 2012).

Phenomenological inquiry best fits the study of the subjects' beliefs, attitudes, needs, and perceptions. 
This research employed semi-structured interviews with school principals having high Need Index scores in their schools. By interviewing principals with high NI scores, I understood the practices used to understand trauma, support students, and remove the barriers to trauma in school environments, most likely to see high volumes of students experiencing trauma. All interviews were video- and audio-recorded and transcribed. Interviews were coded based upon patterns, themes, plausibility, and clustering (Saldana, 2016). Before the interview, each principal completed the trauma-sensitive school checklist questionnaire created by Lesley University Center for Special Education, and Trauma and Learning Policy Initiative of Massachusetts Advocates for Children and the Legal Services Center of Harvard Law School to collect their perspectives of trauma and Trauma-Informed Care within their schools. While many studies have been completed on trauma, utilizing qualitative interviews of teachers' perspectives, research on principals' perspectives has consistently been limited. TIC must be a cultural shift (Baweja et al., 2016; Blitz, Anderson, \& Sasstamonien, 2015; Green, Xuan, Kwong, Holt, \& Comer, 2016). As a JCPS practitioner and researcher, I sought to learn the perspectives of the principal leaders. Through this research, I have gained more insight into their experiences of trauma within their schools and what trauma-sensitive strategies, if any, are utilized to address Trauma-Informed Care for students.

\section{Conceptual Framework}

According to the National Child Traumatic Stress Network Schools Committee (2008), research clearly shows that schools can counter childhood trauma's adverse impacts. Thus, Cole et al. (2005) identify a framework for schools striving to understand 
and respond to childhood trauma issues effectively. The flexible framework was utilized as the conceptual framework. The trauma-informed framework was created by the Trauma Learning Policy Initiative (TLPI), a collaboration between the Massachusetts Advocates for Children and Harvard Law School. TLPI is an organizational tool that enables schools and districts in partnership with families, local community organizations, and outside providers to maintain a whole school focus as they create trauma-sensitive schools. I utilized the flexible framework to analyze how high NI schools organize and implement trauma-informed care practices, procedures, and policies within their institutional structure. According to the school's six core operational functions, Cole et al. (2005) argue that each is critical to any efforts that seek a schoolwide change. The six core operational functions include infrastructure and leadership; professional development; mental health; classroom-based academic strategies; non-academic strategies; policies, procedures, and protocols.

The conceptual framework guiding this research was built on the findings from two recent dissertation studies. First, Fleming (2019) conducted her study to explore the trauma-sensitive model in an elementary and a middle school. The conceptual framework of trauma guided her to utilize the Flexible Framework created by Cole in 2005. Next, Scott (2016) conducted her study to explore the trauma-informed policies, procedures, and practices within six Wisconsin elementary schools. The conceptual framework of trauma-informed schools guided the exploration. Results from Scott's research yielded a more in-depth insight into Trauma-Informed Principles. I chose to utilize the Flexible Framework to gain a more in-depth understanding of principal perspectives on TIC in a large urban district across all grade levels. 


\section{Limitations}

The limitations of this study include accessibility to the principals. Due to the COVID-19 pandemic, schools had to stop traditional instruction and transition to virtual learning platforms. This sudden change caused many challenges for principals. Principals had three weeks of preparation to complete professional development for staff on the new virtual teaching structure; to communicate to parents on modern systems, and organize student schedules to ensure core instruction was prioritized. Seventy-six schools have a high NI score of $42.0 \%$ or higher. Fifty-four schools are elementary; twelve are middle schools; and ten are high schools. The seventy-six schools were invited to participate in the study via a recruitment email. Fourteen agreed to participate. An additional limitation was that the pandemic principals' perspectives might have been different if I had conducted the study at another time. The JCPS District Social-Emotional Learning Director participated in the study to gain insight into how the JCPS district supports schools. The interviews were completed using Microsoft Teams to follow the Center for Disease social-distance guidelines for the pandemic.

\section{Delimitations}

The study is limited to Jefferson County Public Schools with a NI score of $42.0 \%$ or higher. In this district, high NI schools have a high percentage of Exceptional Child Education students, English Language Learners, mobility index rate, and free and reduced-price lunch rate. Traditionally, high NI schools are more likely to see higher volumes of students who have experienced or are currently experiencing trauma. These schools were purposefully selected due to the diverse needs of the students in high-need 
schools. Interviews were limited to building principals with at least two years of experience as a school principal.

\section{Definitions of Terms}

The following terms are used in the context of this study:

Adverse Childhood Experiences (ACEs): is the term used to describe all types of abuse, neglect, and other potentially traumatic experiences that occur to people under the age of 18 .

English Language Learners (ELL): limited English proficient students enrolled in the English as a Second Language program.

Exceptional Child Education (ECE): Jefferson County Public Schools states ECE is a program designed to meet the needs of students who have educational disabilities. Services are provided to students in comprehensive and special education facilities, and a range of programs, techniques, methods, and materials is available for individualized instruction.

Mobility Index Rate: the percentage of students who have withdrawn from another JCPS school during the school year and have re-enrolled in another JCPS school.

Needs Index (NI) score: Jefferson County Public Schools constructs the score based on the percentage total of 15 percentage of Exceptional Child Education students, five percentage of English language learner, 30 percent mobility index rate, and 50 percent free and reduced-price lunch rate. 
School Crisis Response team: a team of school personnel specially trained to support the school environment after a critical incident, such as a student or staff member's death.

Trauma: individual trauma results from an event, series of events, or set of circumstances experienced by an individual as physically or emotionally harmful or lifethreatening and having lasting adverse effects on the individual's functioning and mental, physical, social, emotional, or spiritual well-being.

Trauma-Informed Care: An approach to the care, and the types of interventions utilized in the care, that addresses the effects of trauma, particularly the neurological, psychological, and social impact of trauma, and focuses on creating safety, promoting positive relationships, and improving self-regulation of emotions to manage the results of the trauma.

\section{Summary and Organization of Forthcoming Chapters}

Chapter I provided an introduction to the research topic. Chapter II provides an in-depth examination of the research literature focused on trauma, trauma-informed care, practices, and policies to identify this study's need. In Chapter III, I discuss the phenomenological study methodology I utilized to address principal perspectives on TIC. Chapter IV addresses the analysis that results from the methods discussed in Chapter III. Lastly, Chapter V summarizes the significant findings and implications for policy, practice, and future research. 


\section{CHAPTER II}

\section{LITERATURE REVIEW}

In this phenomenological study, I sought to examine principals' perceptions of trauma, how they address students experiencing trauma, and if and how they utilize Trauma-Informed Care (TIC) to remove barriers to trauma in high Need Index (NI) schools. Specifically, the following research questions will be addressed:

- What understanding do high Need Index school principals have concerning student trauma?

- What are the high Need Index school principals' perceptions of potential strategies that could be implemented to address student trauma within existing schoolwide practices?

- What are high Need Index school principals' perceptions of whether the TraumaInformed Care practices achieve their intended purpose(s), and what do they recommend for the future?

These questions were composed after a thorough review of the literature, which is detailed in this chapter. The first section provides a brief overview of trauma. The second section is a discussion of adverse childhood experiences and their impact on the development of students. The third section addressed how trauma affects students in educational environments. The fourth section examined the concept of and the relevant TIC research on this topic, focusing on the role of schools, districts, and state policies. 
Finally, I will discuss the Trauma-Sensitive Ecology using the Flexible Framework (FF) as the conceptual lens for this research. A summary will be provided in the last section. The following literature review confirms that school principals play a critical role in facilitating TIC procedures, policies, and practices within their schools. TIC initiatives are needed for all students.

\section{Trauma}

Students throughout the United States are experiencing trauma. Schools are an essential point of contact for preventing, identifying, and treating mental health issues, disorders, and trauma. Schools and school staff encounter students daily who are exposed to trauma. Dube (2018) has shown that in the U.S. and worldwide, childhood trauma is a public health crisis. Dube identified childhood adversities, such as abuse, neglect, and related household stressors, which are common interrelated issues and contribute to multiple adverse social, behavioral, and health outcomes throughout the lifespan (2018). The effects of trauma can severely hinder students' academic, career, and social/emotional development. Students exposed to trauma often bring these experiences into the educational setting where they could be mistaken for misbehavior, low academic achievement, and lack of sense of belonging (Cole, 2005).

The Substance Abuse and Mental Health Service Administration's (SAMHSA, 2012) concept of trauma is defined as follows:

Individual trauma results from an event, series of events, or set of circumstances experienced by an individual as physically or emotionally harmful or lifethreatening and having lasting adverse effects on the individual's functioning and 
mental, physical, social, emotional, or spiritual well-being. Trauma in students often manifests outwardly, affecting students' relationships and interactions with peers and adults (p. 2).

Trauma is individualized and is how the person experiencing the event perceives it. Two may share the same traumatic event; however, how the trauma affected the person is individually unique.

In 2014, SAMHSA expanded upon the definition using the three "E's" of trauma: Event, Experience, and Effect. As a result, Soma and Allen (2017) identified an Event:

It may be a single occurrence or be repeated over time and may include the actual or extreme threat of harm. While many events may be potentially traumatizing, we cannot assume that exposure to them leads to post-traumatic stress symptoms and reactions. There are children exposed to similar events that respond very differently from one another (p.viii).

Hence, Soma and Allen point out that while specific events are essential to identify, we must not forget how they are experienced. The authors present a precise evaluation of the Experience:

The Experience or perception of the event by the child determines whether it is a traumatic event. For example, we may view parent incarceration as a potentially traumatizing event. However, if the child of that parent experiences this event as one that provides them with relief, it is not then traumatic (p. viii).

Students may experience trauma in the following three ways: personal, societal, and vicarious (Minero, 2017). Personal trauma is an experience that directly impacts a student (Minero, 2017). These experiences may include child abuse, house fire, or 
homelessness. Students are scared about what has happened during this experience and are unsure of what will happen next. Societal trauma is an experience closely witnessed and often causing you to feel internal hurt for others who have experienced the trauma (Minero, 2017). These experiences may include domestic violence, police brutality, and community violence. Vicarious trauma is the secondary exposure to a traumatic event (Minero, 2017). Recently, students have been overwhelmed with images of the pandemic and social injustice protests happening in their cities and countries.

Soma and Allen (2017) further explain that the Experience then influences the Event's Effect over the short to long term. The students who have a prolonged and exaggerated stress response to any event experience often experience post-traumatic stress symptoms. In discussing Effects, Hamoudi, Murray, Sorensen, and Fontaine (2015) include hypervigilance, inability to cope with daily life, and cognitive functioning disruption as post-traumatic stress symptoms. Perfect, Turley, Carlson, Yohannan, and Gilles (2016) estimate that approximately two out of every three school-age children are likely to have experienced at least one traumatic event by age 17 . Trauma can come in many sources, and not every traumatic event is violent. Witnessing domestic violence, witnessing drug abuse, witnessing a crime, and experiencing abuse (psychological, physical, or sexual) or neglect (emotional or physical) constitute trauma experiences called adverse childhood experiences or ACES.

\section{Adverse Childhood Experiences (ACEs)}

Adverse childhood experiences were found to have tremendous impacts on people affected by these challenges. Felitti et al.'s (1998) study is among the most significant quantitative investigations completed addressing its relationship to the prolonged 
exposure of children to potentially traumatic events that may have an immediate and lifelong impact. From 1995 to 1997, Felitti et al. (1998) studied ten types of trauma:

- emotional abuse

- physical abuse

- sexual abuse

- emotional neglect

- physical neglect

- parental separation/divorce family

- violence

- household substance use

- household mental illness

- incarceration of a household member

Felitti et al. (1998) and Souers and Hall (2016)) revealed a strong correlation between adverse childhood experiences and adult health and, perhaps more significantly, signaled that these ACEs were far more prevalent than previously thought. Students who have experienced ACEs come to schools, and the educators working with the students must be trained to address these traumas. Principals and school leaders should create practices, procedures, and policies to address these ACES and trauma impacting students.

Students of different races and ethnicities do not experience ACEs equally. Nationally, 61 percent of African-American children and 51 percent of Hispanic children have experienced at least one ACE, unlike the 40 percent of Caucasian children and only 23 percent of Asian children (Sacks \& Murphy, 2018). In every subgroup, the prevalence 
of ACEs is lowest among Asian children and, in most cases, is highest among AfricanAmerican children (Sacks \& Murphey, 2018b). ACEs can have immediate and long-term effects on students. Despite being at an increased risk for traumatic stress, ethnic minority youth are less likely to seek support services such as mental health. School plays a vital role in providing services for the students. As students enter our school buildings, they do not shed these challenges.

General trends are apparent in Crosby's (2015) and Torgerson, Love, and Vennon's (2018) studies. Crosby supports the notion that traumatic experiences can impede cognitive, social, and emotional development in childhood, impairing youth academic achievement, behavior, interpersonal skills, and overall school success. Torgerson et al. established a link between a sense of belonging and trauma. The Torgeson et al. study results indicate that a greater sense of belonging may buffer childhood trauma's impact on later mental health outcomes.

ACE literature was advanced by Blodgett and Lanigan (2018) by using school personnel, rather than parent or child, reports to examine the prevalence of ACE exposure in a non-clinical sample of kindergarten through sixth-grade public elementary school children and the association between student ACE profiles and the risk of academic, behavioral, and attendance problems. More than 2,000 students from ten elementary schools participated in this study. Blodgett and Lanigan's utilization of school personnel reports of child ACE exposure minimized family burden and potential intrusion while producing prevalence estimates consistent with the National Survey of Children's Health. Blodgett and Lanigan recruited students through the building principals, following professional development workshops for elementary schools about ACE. Although 
Blodgett and Lanigan's study advances how schools, particularly principals, understood ACEs, it does not address TIC practices, policies, or procedures to address students coming to schools with high ACEs levels. Therefore Pletcher, O'Connor, Swift-Taylor, and DallaPiazza (2019) referenced that the increasing awareness of ACEs allows introducing the concept of trauma-informed care providers to realize the impact of trauma, recognize the signs and symptoms of trauma, and respond with programs that actively resist traumatization.

\section{Impacts of Trauma}

Schools are comprised of students who experience trauma. This trauma significantly influences students' behavior, academic achievement, social-emotional learning, and relationships.

\section{Student Behavior}

Trauma exposure heightens the risk of disruptive behavior. Behavior is always a clue to what the child is experiencing at that moment in time. Soma and Allen (2017) stated that students with a history of traumatic experiences exhibit more unusual oppositional defiant behaviors than children without trauma exposure. Trauma and oppositional defiance have many overlapping symptoms. Souers and Hall (2017) stated problematic behaviors that manifest in the classroom might include the following:

- $\quad$ hypervigilance

- inattention

- detachment

- $\quad$ irritability 
- $\quad$ anger outburst

- restlessness

- $\quad$ impatience

- $\quad$ impulsiveness

- $\quad$ difficulty concentrating

- limited future orientation

- $\quad$ skipping class (p.31)

Soma and Allen advanced the notion that misbehavior is most likely the result of the damaging "physiological impact trauma has on core regulatory systems, compromising a child's ability to regulate and process sensory inputs" (p.27). Soma and Allen observed that traumatized children's analytical capacities are limited under stress, and they react with confusion, withdrawal, and rage. Students who are experiencing trauma may have overlapping symptoms that mimic disruptive behaviors.

Busby, Lambert, and Ialongo (2013) completed a three-year study that examined 491 African-American sixth graders with exposures to community violence. These children displayed more aggressive behaviors and lower academic achievement within the school. Blevins et al.'s (2015) quantitative research advances the notion that students who have exposure to trauma have an increased risk of reckless behavior. For example, 1,145 students experienced the Virginia Tech campus shooting. The online longitudinal study assessed the school shooting's role in the relationship between DSM-IV PTSD symptomatology and increased reckless behavior. Some examples of these behaviors included underage drinking, unprotected sex, and illegal drug usage. The results revealed 188 of the 1145 individuals $(16.4 \%)$ displayed reckless behavior due to trauma exposure. 
Students who experience trauma develop post-traumatic symptomatology that may contribute to increased reckless actions. Reckless behaviors in schools can lead to more out of school suspensions.

In a recent study in the "Hechinger Report," Mader (2019) reported, "50,000 preschoolers were suspended at least once, and at least 17,000 were expelled, according to the Center for American Progress," based on data from the 2016 National Survey of Children's Health. Mader stated that Black children and boys are more likely than their peers to be suspended; this can be attributed to implicit racial bias among educators. Mader highlights that these suspensions do not "improve behavior and can have farreaching consequences - children who are suspended in preschool are more likely to drop out of high school and later be incarcerated." Educators often utilize suspension as a response to problematic behavior. School suspension is a punitive punishment commonly used; it can adversely affect a student's educational well-being and does not improve behavior. As a student's disruptive behavior increases, the principal must determine if the behavior is associated with trauma.

Rossen and Hull (2013) remind us that "trauma changes brain chemistry and neurology and can, therefore, create behaviors that are outside normal functioning, including perfectionism, self-harm, high-risk behavior (e.g., substance abuse), sleep disturbances, aggression, withdrawal, elevated startle response, impatience, impulsivity, irritability, moodiness, and reduced problem-solving skills" (p.29). As noted by Tishelman, Haney, O'Brien, and Blastein (2010), differentiating adverse reactions to trauma from other disturbances in students can be incredibly challenging given many overlapping symptoms; thus, they encourage assessment that utilizes a "trauma lens" 
when evaluating a student's need. Principals should put robust policies, practices, and procedures in place to accurately determine if a student needs behavior modifications or TIC.

Cole et al. (2005) and Wolpow, Johnson, Hertel, and Kincaid (2009) suggested that the administration provide sensitivity to childhood trauma when implementing discipline practices and procedures. Students who are prone to trauma have higher rates of academic and behavior problems. Johnson (2018) supports this argument by stating that traumatic experiences impact a child's relationships and school expectations. Trauma can affect students' academic achievement.

\section{Student Academic Achievement}

Trauma can impact students in academic school performance. Soma and Allen (2017) argue that changes in the brain are why there is a significant correlation between trauma and low academic achievement. Also, Wolpow et al. (2009) acknowledge that trauma has been linked to lower student-achievement test scores and course grades and a higher propensity for school suspension, expulsion, and school failure. Soma and Allen noted that children who have experienced trauma often find it more difficult than peers to focus, the process for understanding, and to recall new information heard during the classroom instruction. Traumatized children direct the energy necessary for concentrating and focusing on schoolwork to suppress the trauma.

An empirical study completed between 2003 and 2013 by Larson, Chapman, Spetz, and Brindis (2017) found children faced a greater risk of low academic achievement, school failure, and mental health disorder when exposed to childhood 
trauma. As can be seen in West, Day, Somers, and Baroni's (2014) qualitative study, which focused on 39 female students ages 14-18 years old who participated in a study to understand students' lived experiences and exposure to trauma and how that has impeded learning in the classroom. West, Day, Somers, and Baroni (2014) provide insight into external and internal behaviors. The students described the causes of behaviors as “environmental influences" and "triggers." West et al. further explain the most common solutions that students gave to reduce externalizing behaviors (such as verbal fights, aggressive posturing, and demonstrating an inclination toward violence as a means to address interpersonal problems) in school settings included "encouraging respect of others" and "improving behavior management to enhance student engagement."

Voisin et al. (2011) found the traumatic experiences of a student who experienced violence exposure to trauma had lower academic achievement. When categorized by gender, females' aggressive behavior was associated with lower grade point average and less student-teacher connectedness. At the same time, males with general psychological problems had less student-teacher connectedness. Female students with internal behaviors such as anxiety achieved lower grade point averages when anxiety levels were high. Perry (2001) draws a parallel between West et al. and Voisin, stating that when traumatized children are in a supportive environment, their IQ scores will improve by 40 to 60 points. As students become stronger academically, they, in turn, will need more robust supports emotionally. 


\section{Student Social-Emotional Learning (SEL)}

Trauma can impact a student's social-emotional functioning. Students cannot "Maslow until they Bloom." Rossen and Hull (2013) state social-emotional functioning: "refers to attributes and skills related to emotional well-being, the ability to manage and regulate emotions, social competence, quality of peer relationships and interactions, and self-esteem, among others. Students cannot learn academics and profit from instruction without first mitigating the impact of social and emotional conditions that interfere with learning" (p.30).

Lubit and Lunit (2019) state that Social-Emotional Learning (SEL) programs support the growth mindset and self-esteem and help students address disruptive feelings and trauma. Schoolwide trauma-informed SEL curricula teach skills to build competence, psychological safety, emotional regulation, de-escalation strategies, and identifying trauma triggers. Soma and Allen (2017) explored how students demonstrated improvement in multiple areas, including the following:

- Enhanced social and emotional skills

- Improved attitudes towards self, schools, and others

- Enhanced positive social behavior

- Reduced conduct problems (misbehavior and aggression)

- $\quad$ Reduced emotional distress (stress and depression)

- Improved academic performance (test scores and school grades) (p.67)

Hutchison, Russell, and Wink (2019) completed a two year longitudinal two-group experimental study on 245 K-8 students utilizing the Aspire Connection Thrive (ACT) program. The goal was to bolster the students' social-emotional skills and resilience over 
time. Hutchison et al. found students living in high-risk areas have increased exposure to trauma. Still, evidence indicates students have lower levels of social-emotional skills compared to those from more advantaged areas.

A wide range of evidence-based SEL programs helps schools facilitate schoolwide programming. Second Steps, Overcoming Obstacles, Believe In You, and PATHS are examples of programs designed to help students impacted by trauma develop an emotional vocabulary to advocate for themselves and differentiate behaviors when facing trauma. Students who experience trauma must have strong relationships with staff to buyin the trauma-informed care practices within the school buildings. Females students responded more intently than their male counterparts. Teacher attrition impacted the results. By implementing SEL into the curriculum, schools can set the foundation for developing healthy relationships with their students.

\section{Student Relationships}

Building relationships with students who experienced trauma can be complicated to establish. Dr. Rita Pierson is an educator who has a famous quote, "kids don't learn from people they don't like. Every child deserves a champion, an adult who will never give up on them, understands the power of connection, and insists that they become the best they can be" (Soma and Allen, 2017). Many of the trauma students have experienced someone close to them. Therefore, it causes a lack of trust and hesitancy to develop a connection. However, Souer and Hall (2016) state, "If we can provide consistency, positivity, and integrity in all our interactions with our students, we'll establish a relationship that is safe enough for them" (p. 96). Soma and Allen (2017) introduced the idea that a "restoration of a sense of safety must be the immediate focus 
and is essential for helping traumatized children heal. At the core of trauma is the overwhelming sense of powerlessness and absence of a sense of safety" (p.78).

Traumatized students may want to isolate themselves and avoid discussing their thoughts and feelings due to shame. Soma and Allen suggested the most significant impact to help students experiencing trauma is creating tangible ways to develop safety.

Educators must recognize and respond to specific student needs. Therefore, Pletcher, O’Connor, Swift-Taylor, and DallaPiazza (2019) referenced that the increasing awareness of ACEs affords an opportunity to introduce TIC providers' concept of the impact of trauma, recognize the signs and symptoms of trauma, and respond with programs that actively resist traumatization. Penner and Wallin (2012) found positive relationships with teachers heavily influence students. Developing positive relationships with teachers who display a caring classroom environment and a sense of safety will improve student behaviors. Schools can help students by building relationships that will ultimately help develop a TIC program.

\section{Trauma-Informed Care (TIC)}

In 2001, Harris and Fallot introduced the term "trauma-informed" to refer to social, behavioral, and mental health services that account for the possibility that clients may have experienced some form of past trauma (Knight, 2018). In response to the wideranging challenges that students may face in their daily lives, trauma-informed schools respond to trauma-exposed students' needs by integrating effective practices, programs, and procedures into all aspects of the organization and culture (Overstreet \& Chafouleas, 
2016). Trauma-Informed Care (TIC) is useful for those who work with traumatized populations, reducing disruptive behaviors, and building relational supports. TIC is a strengths-based delivery approach "that is grounded in an understanding of and responsiveness to the impact of trauma; that emphasizes physical, psychological and emotional safety for both providers and survivors; that creates opportunities for survivors to rebuild a sense of control and empowerment" (Hopper, Bassuk, Olivet, \& Journal, 2010). The Substance Abuse and Mental Health Services Administration (SAMHSA) defines TIC as:

A program, organization, or system that is trauma-informed realizes the widespread impact of trauma and understands potential paths for recovery; recognizes the signs and symptoms of trauma in clients, families, staff, and others involved with the system; and responds by fully integrating knowledge about trauma into policies, procedures, and practices, and seeks to resist retraumatization actively (p.9).

A TIC system recognizes and addresses the impact of trauma on all they serve. Policies and practices are infused and sustain trauma-informed awareness, knowledge, and skills. TIC systems work collaboratively with other organizations to achieve recovery and promote resiliency. Soma and Allen (2017) have shown that "providing students with opportunities to experience safety, consistency, understanding, connections, and support is the true definition of being trauma-informed" (p.3). Soma and Allen highlight that every person in every position "who makes a decision that impacts students or who works directly or indirectly with children in a school system needs to learn about childhood trauma." (p.3) A trauma-informed approach in schools should implement a multi-tier 
service delivery system for students exposed to trauma (Keesler, 2014). Systemic changes to school policies, practices, and procedures can be thought of as the universal, or Tier 1, service delivery (Ridgard, Laracy, DuPaul, Shapiro, \& Power, 2015). Walkley, Cox, and Schools (2013) argue that changes need to be made to the culture, policies, and procedures that govern the school community to adopt a trauma-informed approach. Schools can make these necessary changes to establish a universal tier of service delivery by integrating the four aspects of TIC (i.e., realize trauma exists, recognize the trauma, respond to the trauma, and resist re-traumatization) into school practice (Ridgard et al., 2015).

TIC interventions are emerging, yet they are limited to psycho-education and family center support, health screener, and clinical services. However, a more comprehensive assessment of these interventions in non-clinical settings is needed to understand the impact of trauma on children. Schools are a critical system of support for children who have experienced trauma. More students will continue to walk into schools that mistake trauma for misbehavior if this matter is not addressed. When traumainformed practices are implemented, students impacted by trauma learn to regulate emotions and behaviors, develop healthy relationships, maintain healthy lifestyles, and achieve academically (Rossen \& Hull, 2013).

TIC must be a cultural shift. Previous research has centered on teachers' perspectives. The principal should contribute insight into trauma and trauma-informed practices within the educational institution. Otherwise, an intolerant school culture will be created, not providing support for students in trauma. The principal must integrate an 
understanding of TIC to have a trauma-sensitive school that enforces trauma-informed policies to support all students.

\section{Trauma-Informed Policies}

The federal Substance Abuse and Mental Health Service Administration recommends incorporating trauma awareness and trauma-informed practices within schools. The U.S. House of Representatives approved H. Res. 443 in February 2018. It recognizes the importance of TIC within federal programs and agencies. Special events such as National Trauma Awareness Month and Trauma-Informed Awareness Day were implemented to increase public knowledge of the impact of trauma and ACEs (Maul, 2018). California, Florida, Illinois, Massachusetts, Missouri, Oregon, Pennsylvania, Washington, and Wisconsin have created bills specifically for their TIC policies, approaches, and practices to reduce childhood trauma (Maul, 2018).

Massachusetts has implemented practices, policies, and procedures in the trauma field. In the mid-1990s, Massachusetts Advocates for Children (MAC) found a pattern: students who had experienced trauma were expelled or suspended from school due to their external behaviors. In 2000, the collaboration between the MAC and Harvard Law School was created. This partnership created the Trauma and Learning Policy Initiative (TLPI). This nationally recognized task force has advocated that the Massachusetts legislature complete its mission "to ensure that children impacted by family violence and other adverse childhood experiences succeed in school. To achieve this mission, TLPI advocates for "trauma-sensitive schools," where schoolwide trauma sensitivity is a regular part of how a safe and supportive school" is organized (Trauma and Learning 
Policy Initiative, 2000). TLPI collaborates with schools to help them become traumasensitive, providing training or technical assistance. At its Harvard Education Law Clinic, TLPI also represents individual families in the special education process on behalf of children with disabilities struggling in schools and have experienced adversity (Trauma and Learning Policy Initiative, 2000).

The Task Force's work, MAC, successfully advocated at the Massachusetts legislature for the creation of the Safe and Supportive Learning Environments grant program (MGL c. 69, sec. $1 \mathrm{~N}(\mathrm{~b})$ ) that gave small amounts of money to schools to experiment with trauma-sensitive approaches. The Lesley University's Center for Special Education and MAC collaboration began in 2000 to hold the first-ever conference on the impact of trauma on learning. From that point on, the work on trauma's impact on learning at school gained momentum as MAC worked with an interdisciplinary group of psychologists, educators, and attorneys to draft what would later be published as Helping Traumatized Children Learn (Cole et al., 2005). In 2004, MAC entered into a formal partnership with Harvard Law School called the Trauma and Learning Policy Initiative (TLPI). TLPI engages in a variety of ongoing activities, including helping schools create trauma-sensitive environments; advocating for laws, policies, and funding streams that will enable schools to create trauma-sensitive learning environments; improving traumasensitive approaches to meeting the needs of individual children at school in both regular and special education; and engaging in a public education campaign to teach policymakers, educators, administrators, health and mental health providers and parents about the impact of trauma on learning and the need for trauma-sensitive schools (NYSTeach, 2018). 
In March 2019, Kentucky's Senate Bill 1, the School Safety and Resiliency Act, was signed. This bill was created after the Marshall County High School massive shooting in Kentucky. This bill addresses the hardware and the: "heartware" of school safety. Also, it requires schools to establish trauma-informed approaches. Beginning, July 2021 "a trauma-informed team must be created. It should consist of school administrators, school counselors, school-based mental health service providers, family resource and youth services coordinators, school nurses, and any other school or district personnel" (Kentucky General Assembly, 2019). Senate Bill 1 ensures that all students are known well by at least one adult in the school setting. Building relationships are crucial to addressing trauma. On or before July 1, 2021, each Kentucky Board of education shall develop a plan for implementing a trauma-informed approach. School principals have been tasked with creating procedures, policies, and practices within their school buildings.

\section{Flexible Framework}

The Trauma-Sensitive Ecology of Flexible Framework (FF) will be utilized as the conceptual framework. The trauma-informed framework was created by the Trauma Learning Policy Initiative (TLPI), a collaboration with Massachusetts Advocates for Children and Harvard Law School. It is an organizational tool that enables schools and districts in partnership with families, local community organizations, and outside providers to maintain a whole school focus as they "develop a plan for integrating trauma-sensitive routines and individual supports throughout the school day" (Cole et al., 2005, p.7). The FF provided by TLPI is an organizational tool that is designed to enable schools to develop their trauma-sensitive institutional structure. It gives a guideline for 
establishing a schoolwide practice. When educators "have a better understanding of trauma they can form effective linkages with a mental health professional who has an expertise in the field; make full use of available resources; and advocate for new resources and particular interventions that directly meet the needs of their students" (Cole et al., 2005, p.7). Cole (2015) states six core operational functions: infrastructure and leadership; professional development; mental health; classroom-based academic strategies; nonacademic strategies; and policies, procedures, and protocols, which are critical when creating a trauma-sensitive school. The six components of the FF are described below:

- Infrastructure and Leadership - Administration should have direct participation in the strategic planning; input from all stakeholders should be included; and trauma-sensitive approaches should involve the school operations.

- Professional Development - Professional development is critical for all school members in the school community. Rossen and Hull (2013) state that strengthening the relationships between students and adults teaches staff to help students modulate their emotions and utilize outside resources to support students. Cole (2015) suggested a few examples of meaningful professional development areas that include understanding the prevalence and impact of trauma; techniques for strengthening relationships between children and adults; and alternatives to punitive disciplinary practices.

- Role of Mental Health - School psychologists, school counselors, social workers, mental health practitioners, and community agencies can help 
identify and effectively coordinate mental health resources to allow students to participate fully in the school community. Equally important are resources that support and provide staff with the opportunity to discuss students' needs confidently and reflect on how their work affects their own lives.

- Classroom-Based Academic Strategies - Students who experience trauma often bring those adverse experiences into the classroom. Some students exhibit behaviors that are similar to misbehavior, while others indicate no real issues. Creating a safe learning environment for all students supports socialskills development and enhances self-regulation (Durlak et al., 2011).

- Non-academic Strategies - Relationships are essential when working with all students. Students who suffer from trauma need to foster a sense of safety with a caring adult. "Often, these relationships are easier built around nonacademic issues, as often the child impacted by traumatic experiences will struggle to be successful with academic material and associate academics with negative emotions" (Rossen \& Hull, 2013, p. 259). Mentoring programs and advisory groups are examples of non-academic strategies to build students' relationships.

- Policies, Procedures, and Protocols - Cole (2005) suggests that schools should review and implement policies, procedures, and protocols within their discipline policies, culture, climate, safety plans, and schoolwide expectations to ensure they are trauma-sensitive. 


\section{Summary of Literature Review}

Many issues affect a student who experiences trauma within the school. Trauma can affect a student's academic achievement, behavioral outcomes, social-emotional learning, and building relationships. The Adverse Childhood Experiences (ACES) highlighted at the beginning of the literature review explain how traumatic events can have lasting effects on students. Research consistently indicates that the higher the ACE scores students experience, the more disrupted are neurodevelopment; social, emotional, and cognitive impairment; adoption of health-risk behavior; diseases, disability, and social problems and early death. High NI school principals serve a disproportionate number of students with higher Exceptional Child Education services, English language learners, mobility index rates, and free and reduced lunch price rates. School principals must recognize the impact of trauma on students and embrace trauma-informed practices to address the challenges that present themselves within the school building. Being a trauma-sensitive school requires a combination of recognizing the trauma and addressing it with practices, procedures, and policies.

Few studies have examined the views of school principals' perceptions of trauma and how it impacts students and the school community. Moon et al. (2017) argue that it is imperative to assess school administrators' perceptions of and attitudes toward mental health promotion in schools. Trauma-informed practices have more significant effects if they involve the entire organization, including supervisors, and change the way individuals in organizations relate to each other (Whitaker et al., 2019). Supervisors 
represent the administration teams in the school setting. It is crucial to obtain administrators' perspectives to understand the importance of TIC procedures, practices, and schools' policies. Therefore, through this qualitative research, I sought to advance the knowledge of trauma practices by adding what has been described as limited research on principals' perceptions of TIC.

\section{Summary of Chapter}

This chapter presented literature related to trauma, adverse childhood experiences, traumas' impact on education, TIC, and effects on the educational environment. The Flexible Framework is the conceptual framework to guide this study. Chapter three outlines the methodology of the study. Data collection and analysis will be presented. 


\section{CHAPTER III METHODOLOGY}

This study's goals examined K-12 principals' perceptions of their knowledge of trauma, how they address students experiencing trauma, and if and how they utilize Trauma-Informed Care (TIC) to remove barriers to trauma in high Need Index (NI) schools. The data collected provided answers to the following research questions:

- What understanding do high Need Index school principals have concerning student trauma?

- What are the high Need Index school principals' perceptions of potential strategies that could be implemented to address student trauma within existing schoolwide practices?

- What are the high Need Index schools the principals' perceptions of whether the trauma-informed care practices achieve their intended purpose(s), and what do they recommend for the future?

This chapter represents the phenomenological research design specific to this study. This chapter includes an explanation and rationale of methodological features around the following areas: research design, context, sampling strategy, data collection, data analysis, delimitations, and methodology limitations. The chapter culminates with the researcher's positionality and a summary. 


\section{Research Design}

\section{Phenomenological Research}

German philosopher Edmund Husserl developed phenomenology and that this philosophy is the foundation for phenomenological research. The purpose of a phenomenological study is to investigate the ordinary meaning of people's lived experiences to identify the essence of human experience or phenomena described by research participants (Bloomberg \& Volpe, 2012). Van Manan (2014) describes phenomenological research as beginning "with wonder at what gives itself and how something gives itself. It can only be pursued while surrounding a state of wonder" (p.27). The researcher focuses on essential themes by "bracketing" their own experiences with the phenomenon to understand the participants' experience. Phenomenological research uncovers meaning while articulating procedures and systems of the lived experience (Creswell, 2014). The phenomenological study's primary purpose is to obtain a view of the research participants' life-worlds and understand their meanings (Johnson \& Christensen, 2014; p. 1799).

\section{The Rationale for Using Phenomenological Research Design}

This study is a qualitative study that utilized a phenomenological analysis to understand the process, practices, and policies school principals implement to address trauma within a large, urban school district. As the researcher, I wanted to resonate with the themes composed of the interviews. The phenomenological research paradigm was utilized in this study to gather the school principals' understanding of trauma and 
Trauma-Informed Care (TIC). This study illustrated the impact trauma can have on students and the educational experience by looking at existing schoolwide practices or past practices within their assigned schools. This research design utilized multiple principals' perspectives to draw on detailed articles within each school. This study design included a questionnaire and in-depth interviews, both standard for phenomenological studies (Johnson \& Christensen, 2014; Patton, 2015). With an increased interest in TIC or trauma-sensitive schools in education in recent years, it's vital to get principals' understanding of this phenomenon.

My overall aim in this study was to examined principals' perceptions of trauma and how they addressed students experiencing trauma. Students enter schools with invisible backpacks filled with traumas, and principals must implement practices to address these barriers students bring to school. The results of this study will be used to create a guidebook for principals and school district personnel to develop traumainformed practices, procedures, and policies to address traumas in a large urban school district.

\section{Conceptual Framework}

The Flexible Framework (FF) was utilized as my conceptual framework. The framework is a systemic overview of school operations and provides a process for reviewing a school's impact on student success (Cole et al., 2005). The six components of the flexible framework contributed to creating a safe and supportive school ecology: infrastructure and leadership; professional development; the role of mental health; classroom-based academic strategies; non-academic strategies; and policies, procedures, 
and protocols - the conceptual framework guided the interview questions and data analysis.

\section{Context of the Study}

This study was conducted in Jefferson County Public Schools (JCPS), a large urban public school district in the United States' southeastern region. The selected community is the 28th largest school district in the United States and the largest and most diverse school district in the state, with 148 languages spoken by students and 9,120 English Language Learner students. JCPS approximately 100,000 students, with 12,400 qualified for Exceptional Child Education and 5,200 classified as homeless. JCPS comprises 170 schools in the 2019-2020 school year, with 93 schools labeled as Title I schools.

In Kentucky, 219,000 students live in poverty; half of the incoming kindergartners are not ready to learn; and a record-high number of students are in foster care (Kelly, 2019). Subsequently, Jensen's (2009) discussion of poverty openly acknowledges that impoverished families tend to be a higher prevalence of adversities and later lead to students' poor school performance and behavior. Homelessness, economic instability, immigration, and neglect are examples of trauma issues that students may experience. These hardships lead to more student mobility. The mobility index rate is determined by the percentage of students who have withdrawn from another JCPS school during the school year and have re-enrolled in another JCPS school. Within the district, the mobility index rate is $8.9 \%$ for elementary school, $9.2 \%$ for middle 
school, and $6.9 \%$ for high school students. These experiences often undermine students' ability to learn, manage behaviors, and build relationships.

Within JCPS, trauma is often mistaken for behavior, specifically for children of color. Some students may respond with increased aggression, viewed as a viable way to solve problems and resolve conflict, avoid classroom activities and assignments, or difficulty focusing or concentrating on academic work (Rossen and Hull, 2013 p. 97). According to the district's Envision Equity scorecard, Black males eligible for free or reduced-price lunch make up the largest share of total suspensions, accounting for $36 \%$ of all suspensions in 2016-17, though Black males eligible for free or reduced-price lunch account for only about $15 \%$ of the district's population. The district's Envision Equity scorecard measures and analyzes school data in the focus areas to improve culture, increase capacity, and learn, grow, and develop. The five domains for analysis are school climate and culture, literacy, discipline, college and career readiness, and opportunities and access. Perry and Morris (2014) suggest that suspension exacerbates consequences such as apathy, anger, and disengagement, which increases the likelihood of more suspensions.

\section{Participants}

The targeted participants were identified using purposeful sampling. This study's participants are school principals from high NI schools within Jefferson County Public Schools (JCPS). The schools were selected based on NI scores of $42.0 \%$ or higher; seventy-six schools with high NI principles fit the research criteria. Also, principals were required to have at least two years of experience as a principal. All principals were 
invited to participate via a recruitment email. To circumvent a lack of participants, I held preliminary discussions with many principals to get their feedback on participating in the studying. Fourteen principals were interviewed and completed the trauma-sensitive school checklist. Data sources include K-12 school principal interviews; an interview with the district director for social-emotional learning; and a trauma-sensitive checklist questionnaire tool analysis completed by the principals. (See Appendix F: Recruitment Email)

\section{Data Collection}

To conduct this research, I utilized multiple sources of data. Various data collection sources and analyses provide a means to strengthen triangulation reliability and internal validity (Merriam, 1988). I completed semi-structured interviews with principals; interviews with the social-emotional district director; and the Trauma-Sensitive School Checklist questionnaire completed by principals. The Trauma-Sensitive School Checklist questionnaire was created in 2005 by, Trauma and Learning Policy Initiative (TLPI) of Massachusetts Advocates for Children and the Legal Services Center of Harvard Law School and Lesley University's Center for Special Education. The questionnaire helps schools assess where they are and where they need to create more robust practices for a trauma-sensitive school. The informed consent (Appendix C) was signed electronically via Survey Monkey before the principals completed the questionnaire. Principals completed the Trauma-Sensitive School Checklist Questionnaire (Appendix A) before the interview to gain their perspectives on trauma within their assigned schools. The Trauma-Sensitive School Checklist Questionnaire is an open-access survey open to the public. The Trauma-Sensitive School Checklist Questionnaire was completed via Survey 
Monkey. The results helped to guide the interview. The Trauma-Sensitive School

Checklist Questionnaire evaluates five areas: (1) schoolwide policies and practices, (2) classroom strategies and techniques, (3) collaboration and linkages with mental health, (4) family partnerships, and (5) community linkages.

\section{Semi-Structured Interviews}

Semi-structured interviews were utilized as a fundamental method of data collection. Due to the COVID-19 pandemic, individual interviews were held virtually using Microsoft Teams. The interview questions were modified by the study completed by Scott (2016) to explore the trauma-informed policies, procedures, and practices within six Wisconsin elementary schools. My interview questions specifically addressed the large urban school district, and therefore, permission was not sought. Open-ended questions were framed to invite in-depth conversation. Interview questions analyzed the principal's perceptions of trauma-informed processes, practices, and policies within each school. The questions focused on trauma, Trauma-Informed Care, implementation of Trauma-Informed Care, principal responsibilities, academic and non-academic barriers, and professional development. (Appendix D provides the open guided interview questions, alignment to research questions, and the Flexible Framework).

Due to the COVID-19 pandemic, the governor of Kentucky mandated schools close in-person learning to virtual platforms and ordered social distance orders (McLaren \& Krauth, 2020). Thus, interviews were held virtually via Microsoft Teams. Interviews were audio- and video-recorded. All participants were provided an informed consent form (Appendix C: Informed Consent) and interview protocols (Appendix D: Principal 
Interview Protocol, Appendix E: Social-Emotional Director Interview Protocol). Informed consent was signed electronically via Survey Monkey. Pseudonyms were assigned to principals and schools to provide confidentiality.

\section{Data Analysis}

Interviews were recorded and transcribed using a transcription service-principals reviewed transcriptions for validation and ethical consideration (Allen, 2017). Interviews were transcribed by Rev and read through for general content. Interviews were analyzed using the conceptual framework, Flexible Framework. The Trauma-Sensitive School Checklist's five areas align with the six components of the Flexible Framework. This research data analysis occurred through transcriptions, coding, analyzing, and thematic themes were identified (Miles, Huberman, \& Saldana, 2014). Inductive and deductive coding looked for themes in the questionnaire responses and interviews. Inductive coding looks for short words and phrases, and deductive coding uses a provisional list of codes (Fereday \& Muir-Cochrane, 2006). I coded the checklist for themes that emerged from the principals' responses. The themes from the interview fit into the six principles of the framework. In Vivo, a coding method was utilized to analyze interviews. The root of In Vivo coding is "in that which it is alive," and as a code refers to the word or short phrase from the actual language found in the qualitative data record, "the term used by [participants] themselves" (Strauss, 1987, p.33). In Vivo, coding honors the participants' voice and helps preserve participants' meaning and actions in the coding itself. A clear picture of principals' understanding of student trauma and its implications for students and schools was developed into broad themes. 


\section{Qualitative Validity and Ethical Consideration}

I utilized data triangulation through multiple principal interviews, interviews with the district social-emotional director, trauma questionnaire data, and participant checked transcriptions to ensure the credibility and validity of the data. As our state embraces the new changes by school safety legislation, the Kentucky General Assembly directs all public schools to adopt a trauma-informed education approach by July 2021 . Interviewing principals and district social-emotional directors would allow them to voice their perceptions of the district's support or lack thereof and their sentiments about the success and failures of Trauma-Informed Care within their buildings and the community. Due to the COVID-19 pandemic and social distant guidelines, "I had to honor each participant sufficiently to enable comparison with the experiences of other persons in the study" (Trainer \& Graue, 2013, p.189). For this reason, I utilized pseudonyms to protect principal and school identities to avoid facing a conflict between the district and upcoming state policies.

This study required the approval of the Institutional Review Board (IRB) of the University of Louisville and Jefferson County Public Schools Districts. Participation in this study was voluntary, and no incentives were provided. Before the interview and following IRB approval, participants were provided informed consent (Appendix C includes the Informed Consent, Appendix C consists of the Interview Protocol for School Principals, and Appendix D includes Interview Protocol for District Social-Emotional Director). All interviews were video-and-audio recorded. The online format was followed due to social distant guidelines in place due to the COVID-19 pandemic. 


\section{Researcher Positionality}

When researching people, one must ensure that one's own biases do not impede the inquiry. Milner (2007) suggests that researchers be actively engaged, thoughtful, and forthright regarding possible tension when conducting research. As I completed my study, I considered my positionality as an African-American woman who is a mother of three African-American children and wife to an African-American man. I have recently experienced the trauma of my brother-in-law's death, which was played out in the media, quarantine from the COVID-19 pandemic, and social unrest in my city. Based on my trauma, I can connect and understand the traumas our students are facing.

As an administrator in a large urban school district, I often see students who look like me labeled as "bad." As a professional school counselor, I am provided professional development and training on trauma-informed care more frequently than building principals. Often trauma can mask itself as misbehavior. Behavior is always a clue to what the child is experiencing at that moment in time. Soma and Allen (2017) stated that students with a history of traumatic experiences exhibit more unusual oppositional defiant behaviors than children without trauma exposure. Trauma affects students academically, behaviorally, socially, and emotionally. I refuse to label students "bad." Milner (2007) suggests that researchers should possess or pursue more in-depth racial and cultural knowledge about themselves and the community or the people they are studying. In my research, I utilize Trauma-Informed Care to provide an understanding of the roots of the trauma. 
As a counselor, I have always worked very closely with the principals. My connectedness allows the principals to be comfortable and honest in our discussions on trauma. Counselors are often called upon to address students' academic, social/emotional, and college and/or career areas. As a Counselor, I often work in collaboration with my principal on schoolwide efforts. The principal and I must have excellent communication, respect, and trust. I have had the opportunity to work with four school principals in my eleven-year tenure within the district. I also have the chance to join my principal at another school to help with turnaround efforts. I would have been asked to follow this principal unless we have a trusting relationship, and I effectively worked with students and families.

I must be mindful of my own bias due to my understanding of trauma and not make decisions or interpretations of what the principal should say or wanted to say. Although I have personally experienced traumas, I always rely on my professional school counselor training and follow the code of ethics. We are trained professionals not to show bias in a situation and fully be attentive and provide the best resources possible for our helping person. In my case, I only listened and removed my own biases.

My research interest is beneficial to all principals due to Senate Bill 1, the School Safety and Resiliency Act. On or before July 1, 2021, each Kentucky board of education shall develop a plan for implementing a trauma-informed approach. School principals have been tasked with creating procedures, policies, and practices within their school buildings. This Bill addresses the hardware and the "heartware" of school safety. Also, it requires principals to establish trauma-informed approaches within their schools. 
Principals must consider all factors when creating policies within their buildings, such as students' race, students' socioeconomic level, teacher's experience, funding, community support, etc. These could be brought barriers when creating their Trauma-Informed Care policies or could provide the community resources to provide structures to support students. Therefore, my study's purpose is to highlight principals' perceptions of trauma, how they address students experiencing trauma, and if and how they utilize TraumaInformed Care to remove barriers to trauma in high Need Index schools.

\section{Summary of Methodology}

This study utilized narrative phenomenology to explore fourteen school principals' lived experiences and one district social-emotional director. This research focused on finding Trauma-Informed Care practices, procedures, and policies implemented within the schools. 


\section{CHAPTER IV}

\section{FINDINGS}

\section{Introduction}

This qualitative study examined K-12 principals' perceptions of trauma, how they address students experiencing trauma, and if and how they utilize trauma-informed practices to remove barriers students face during trauma in high Need Index (NI) schools. I present the research in alignment with the conceptual framework, "Flexible Framework" (FF), from Cole et al. (2005). The six components of the FF contributed to creating a safe and supportive school ecology. The components are as follows: infrastructure and leadership; professional development; the role of mental health; classroom-based academic strategies; non-academic strategies; and policies, procedures, and protocols. Results from the data were used to answer the following research questions:

- What understanding do high Need Index school principals have concerning student trauma?

- What are the high Need Index school principals' perceptions of potential strategies that could be implemented to address student trauma within existing schoolwide practices?

- What are the high Need Index school principals' perceptions of whether the trauma-informed care practices achieve their intended purpose(s), and what do they recommend for the future? 
This study was conducted in the Jefferson County Public School (JCPS) District, the largest urban school district in the southeastern United States. I explored the lived experiences of K-12 school principals who have students of high need. To identify principals for the study, I examined the high NI scores from 170 schools within the selected school district. The NI score is calculated based upon the percentage of free and reduced-price lunch students (FRL); percentage total of Exceptional Child Education students (ECE); percentage total of English Language Learners (ELL); and mobility index rate (MIR). The district calculation is FRL (.50) + ECE (.15) + ELL (.05) + MIR (.30). All JCPS principals with high NI, over $42.0 \%$, were invited to participate in the study. Sixty-seven schools met the qualifications for the study. I interviewed 15 participants, and 14 of them are school principals at different schools within the Jefferson County Public School District. The fifteenth participant was the social-emotional director, responsible for overseeing social and emotional learning and Trauma-Informed Care (TIC) needs across the district. Pseudonyms were used for the school, and participants were interviewed for this study.

Each school principal participated in an online questionnaire called the TraumaSensitive School Checklist questionnaire via Survey Monkey (Appendix A). The questionnaire was completed before the interview to provide a context for trauma in each school studied. The questionnaire was analyzed and referred to during the participants' discussions to gain perspective on principals' understanding of trauma and TIC. The trauma questionnaire was compared to the interview responses to triangulate the data. Each principal and the social-emotional director participated in a semi-structured interview via Microsoft Teams. 
At the time of the discussions, our country was amid the COVID-19 pandemic. The COVID-19 pandemic is considered the most catastrophic global health calamity of the century and the most significant challenge humankind has faced since World War II (Chakraborty \& Marity, 2020). In March 2020, the governor of Kentucky recommended that all school superintendents cease in-person classes for an extended period. The district launched its first online and distance learning program called Non-Traditional Instruction (NTI) or NTI 1.0. The district has approximately 100,000 students, with 12,400 students qualified for Exceptional Child Education; 5,200 classified as homeless; 9,120 English Language Learners; and over 61,400 students on free and reduced-price lunch. During the pandemic, access to technology is essential in student success in remote learning participation. Students of color, those from low-income families, English Language Learners, and students with mild to moderate disabilities have even less access to the technology needed for virtual learning than their peers (TNTP Opportunity Myth Report, 2020). In general, communities of color are disproportionately impacted by slow internet speeds, lack of internet access, and a limited number of computers in the home. This technology divide exacerbated existing disparities and trauma with our students. A limited number of Chromebooks were available for students who did not have access to a computer. The school district distributed up to 25,000 Chromebooks to complete online education and combat some remote learning barriers.

As principals were wrapping up a complicated school year, I explored the lived experiences of their journey during the interview. Principals shared the challenge with meeting students' academic, social/emotional needs, and behavior expectations within schools and virtually. In addition to COVID-19 and NTI, families are experiencing racial 
trauma, both vicariously and directly. Families have been inundated with illustrations on television and social media platforms of deaths of black and brown people, police brutality, and riots. Students saw George Floyd, a Black man, lose his life at the hands of the people who are meant to protect and serve them. Immediately following, the city of Louisville, Kentucky, experienced social unrest due to the death of Breonna Taylor, a 26year-old Black female, killed in another police shooting.

As of March 2020, Attorney General Daniel Cameron did not order the three officers involved in the shooting to be arrested. The officers were placed on administrative reassignment pending the outcome of the investigation. This case has drawn national attention to the city, calling for police accountability. In September 2020, Attorney Daniel Cameron indicted one of the three police officers on first-degree wanton endangerment charges for firing shots into the neighbor's apartment. None of the police officers involved were charged with the murder of Breonna Taylor. Several protests erupted due to the death of Breonna Taylor. Mayor Greg Fisher of Louisville, Kentucky, enforced a citywide curfew; this did not quell the community uprising. These events triggered traumas in many students centered around discrimination, fear, anxiety, behavior, and social injustice - all amid a pandemic and Non-Traditional Instruction (NTI).

A brief description of each principals' demographics (Table 1) and a quote highlighting some of their lived experiences of student trauma during NTI during a pandemic and social unrest are featured here to introduce the participants. These quotes highlight the crucial importance of understanding trauma and participants' first end of school year reflections. 
Table 1.

Demographic Information of Participants

\begin{tabular}{|c|c|c|c|c|c|}
\hline Principal Name & $\begin{array}{l}\text { Years As } \\
\text { Principal }\end{array}$ & $\begin{array}{l}\text { School } \\
\text { Name }\end{array}$ & Level & $\begin{array}{l}\text { Trauma } \\
\text { Trained }\end{array}$ & $\begin{array}{c}\text { Needs } \\
\text { Index } \\
\text { Score \% }\end{array}$ \\
\hline Principal Baker & 5 & Wood Fern & Elementary & Yes & 55 \\
\hline Principal Irwin & 3 & $\begin{array}{c}\text { Jewel } \\
\text { Orchard }\end{array}$ & Elementary & No & 44 \\
\hline Principal Dunn & 14 & Hemlock & Elementary & Yes & 49 \\
\hline Principal Ebanks & 8 & Red Maple & Elementary & No & 53 \\
\hline Principal Earnhart & 9 & $\begin{array}{l}\text { Yellow } \\
\text { Birch }\end{array}$ & Elementary & Yes* & 51 \\
\hline Principal Yalden & 7 & $\begin{array}{l}\text { Black } \\
\text { Cherry }\end{array}$ & Elementary & Yes* & 55 \\
\hline Principal Steward & 6 & $\begin{array}{l}\text { Wake } \\
\text { Robin }\end{array}$ & Middle & Yes & 42 \\
\hline Principal Clark & 8 & $\begin{array}{c}\text { Feather } \\
\text { Grass }\end{array}$ & Middle & No & 43 \\
\hline Principal Scott & 9 & Gardenia & Middle & No & 43 \\
\hline Principal Gibson & 7 & $\begin{array}{l}\text { American } \\
\text { Elm }\end{array}$ & Middle & No & 42 \\
\hline Principal Oakley & 11 & Sycamore & High & Yes & 50 \\
\hline Principal Myers & 11 & Heath & High & No & 43 \\
\hline Principal Earwood & 18 & River Oats & High & No & 49 \\
\hline Principal Reed & 4 & Hornbeam & High & No & 43 \\
\hline
\end{tabular}


Principal Baker/Wood Fern Elementary School: We have several children who we know have lost family members during non-traditional instruction (NTI). We had six kids who had a family member pass away from COVID.

Principal Irwin/Jewel Orchard Elementary School: Families struggle with just instruction and technology. Many had challenges with the content and the curriculum. I've had families reach out to me not being able to follow along with the coursework that the teachers are teaching, and they wanted packets, but then they struggle with getting to the food site to get packets. I had some situations where, and I didn't know this until later, an older sibling took a kid to a food site to get a packet, and they wouldn't give them the packet because they had to have an adult with them.

Principal Dunn/Hemlock Elementary School: If we start at the beginning of the pandemic, little students, of course, being scared, but I think more than anything, we are the safe security for so many of our kids. As a result, they not being here daily; that was hard on them.

Principal Ebanks/Red Maple Elementary School: Our kids miss the social interaction, seeing, not understanding some of the assignments. Some of our parents were frustrated because we were calling every day, kids checking out too.

Principal Earnhart/Yellow Birch Elementary School: We had to make adjustments and ensure that our kids, families, and basic needs were met. It was great that some of our families were able to receive the Chromebooks for their connections. Still, during the first two weeks or so for NTI, we were connecting with our families to make sure their well-being was okay, not even getting to the learning part, or not even getting to the academic side of anything at that time. 
Principal Yalden/Black Cherry Elementary School: For the first time in our building, the term "homelessness" was used regarding trauma. This traumatic event has effected lots of my students.

Principal Steward/Wake Robin Middle School: I think NTI is very stressful, very traumatic for many of our kids, especially middle school kids, because they're so social. They have been without their friends, their classmates. The recent protests and then just all the news that kids are hearing. I'm sure parents are talking about it at home. I know I talk about it with my kids at home.

Principal Clark/Feather Grass Middle School: Since we went into NTI, all of our counselors reported that...So we have a reporting system where kids could log in and share how they were feeling. Anyone who reported being sad or anxious or anything along those lines would follow up with a phone call. But unfortunately, in many cases, we couldn't get past the parent, and the parent would say that child is okay.

Principal Scott/Gardenia Middle School: I think NTI was very difficult. I think it was as traumatic for our students as it was for us as adults. I know I've talked to several staff members just about the lack of connectivity.

Principal Gibson/American Elm Middle School: I have two colleagues who had lost relatives to COVID. They are coming back to school with trauma.

Principal Oakley/Sycamore High School: Well, with COVID, the most recent trauma now is connectivity to school, but past that it is, the big one is gun and community violence.

Principal Myers/Heath High School: I think most recently, my school has been rocked by community-based trauma that is seated in gang violence, friends that they have 
that, whether they're making bad choices or not, but the loss of that. One of those murders took place during NTI.

Principal Earwood/River Oats High School: I'm telling you that we've had a student who was shot and killed in the streets from my school. And that happened during NTI. But then also just the trauma of our kids not being together physically, it is that emotional piece of trauma, they've had that to deal with.

Principal Reed/Hornbeam High School: I believe the trauma was endured from students throughout NTI were things like picking up the workload to support the family, trying to navigate online classes when they're used to the support of in-person interaction with teachers.

District Social-Emotional Director: We first were asked to quarantine in March; the first thing the district did was to reach out to our assistant superintendent to ask us (Social Emotional Department) if we have any course material around the impact or the effects of trauma on this whole thing with the pandemic and COVID-19. We immediately began to consult with our people from the University of Kentucky, asking them if they had anything. And so they did provide us some articles that we were able to send to the district. They farmed materials regarding kids with those trauma exposures.

\section{Trauma-Sensitive School Checklist Questionnaire}

The Trauma-Sensitive School Checklist questionnaire is an easy-to-use checklist created by Lesley University and the Trauma and Learning Policy Initiative of Massachusetts Advocates for Children and the Legal Services Center of Harvard Law School. The questionnaire allowed principals to reflect on how trauma and TraumaInformed Care is addressed within their schools. The questionnaire addressed five 
categories-school-wide policies and practices, classroom strategies and techniques, collaborations and linkages with mental health, family partnerships, and community linkages. Each question had several components; principals had to determine if those elements were in place. Principals had four choices to determine if elements were in place:

- Element is not at all in place.

- Element is partially in place.

- Element is mostly in place.

- Element is fully in place.

For this research, the questionnaire was used to gauge principals' understanding of trauma and Trauma-Informed Care. The Trauma-Sensitive School Checklist Questionnaire aligns with the Flexible Framework. The Trauma-Sensitive School Checklist Questionnaire has five components that are parallel to the six components of the Flexible Framework. A brief comparison of the questionnaire and framework are listed below in Table 2 .

\section{Table 2.}

Trauma-Sensitive School Checklist Questionnaire and Flexible Framework Alignment

\begin{tabular}{ll}
\hline $\begin{array}{l}\text { Trauma-Sensitive School } \\
\text { Checklist Questionnaire }\end{array}$ & Flexible \\
Framework
\end{tabular}




\section{Theme Outline}

The research data collected from the principal and social-emotional director interviews, Trauma-Sensitive School Checklist Questionnaires, and field notes from observation of principals' non-verbal reactions uncovered principals' perceptions of trauma. They revealed some differences in their approach, implementation, and barriers to Trauma-Informed Care. Initial themes came from the Flexible Framework.

\section{Experiences}

Trauma is generally defined as a perceived distressing or disturbing experience or life-threatening event. Trauma is real, prevalent, complicated, and expresses itself in different ways. In this study, I found that the principals overwhelmingly responded to students experiencing trauma to impact the student significantly. Everyone experiences trauma personally, in which they are hurt by what has happened, and often try to understand where they stand and what to say. The cognitive effects of trauma can cause lasting repercussions on the brain. When distressing or disturbing experiences trigger students' minds, adrenaline and cortisol are released in the body, starting a flight, fight, or freeze response. Many of the traumas students are experiencing occur outside of their control, leaving students in survival mode when triggered.

Each school has a Need-Index score of $42 \%$ or higher; however, each school's cultural capital is unique, specifically because students have various socio-economic, religious, financial, and spiritual-affiliation backgrounds. The effects of this diverse, 
unique cultural capital are reflected in schools' discussions on trauma. All principals provided a different generalized definition of trauma. Each included the common theme of the "experiences" students faced. Principal Dunn shared a description of trauma as "an experience that someone goes through that manifests itself to physical or emotional disturbance." Principal Baker echoed this, stating, "trauma is an experience that causes children to have long-lasting impacts socially, emotionally, or behaviorally."

Similarly, Principal Myers acknowledges "that trauma doesn't define any race or class; it doesn't know any of those parameters. We're all susceptible to that. I feel like it's something that happens more to someone than it is that you inflict on yourself. You don't have much control over it. It can cause just severe damage, whether it's mental, physical, or emotional." Principal Yalden supported this point by emphasizing that students "experience countless violence, exposure to domestic violence, parent incarceration, some of my students' families have been murdered. Experience poverty, homelessness, drugs, alcohol, or abuse by family members." Principal Gibson similarly wrapped up by stating, "trauma is ambiguous because it is individualized. You can't just give a definition for it, but in my eyes, it's whatever that person has gone through that can alter them. So trauma, very individualized, and even certain trauma levels depend on the person and the actual event.”

The six elementary principals identified common themes of neglect, homelessness, and hunger when describing students' generalized trauma exposures. Elementary students were experiencing a direct impact of trauma. The immediate effect of trauma causes a sensory overload to the brain leading to a fight, flight (flee), or fright response. Psychological fears trigger these physiological reactions. Usually, the first 
response is to fight to gain a sense of safety (Rossen \& Hull, 2013). Often, behavioral expressions of distress are displayed. Principal Baker mirrored this, stating that students who experience trauma react with an extreme outburst in behavior, from throwing things, escaping from classrooms, yelling, screaming, fighting, hitting themselves, hitting others, and "banging heads into the walls, or the exact opposite. We have some kids who've become wholly withdrawn. They don't participate in class; they don't interact with peers; they don't have social groups; they're very anxious." Often students flee to run away from the situation. Students running from the classroom or having an outburst to leave the classroom can happen when they perceive they are in imminent physical danger.

Elementary students do not have the voice or vocabulary to advocate for themselves. In addition, to fight and flight responses, freeze responses occur. Students may restrict breathing, have pale skin, or express ailments such as a psychosomatic stomachache or headaches that do not exist. Principal Yalden drew on experience with students, stating, "The inability of students to explain why they are, the way they're feeling or why they have the outbursts or the way they're acting. Especially the younger kids. Our primary age kids don't have the ability yet to explain why they're feeling the way they're feeling or why doing what they're doing."

Middle school principals strongly emphasized that students' experiences with trauma were the death of a family member and caused an emotional response. Often this trauma is witnessed or closely related to the student, therefore causing an emotional response. Principal Steward describes a delicate experience with a student: "Anything from maybe the death of a parent, death of a family member...maybe grandma has been taking care of the kids, and now she's recently passed away. Who are they going to live 
with? Who are they going home to? I've had a few students who have come to me, and they'll say, 'Oh, Principal Steward, I won't be here tomorrow. I have to go to my dad's funeral. He got shot two weeks ago.' They say it like it's just nothing - like it's just part of the plan even."

Principal Scott identified students' reactions who experienced or witnessed relational trauma. "I can think of one student in particular. We know the anniversary of when he lost his father. We have another student we know the anniversary of when he lost a cousin, so the first year that we met them, we didn't realize either situation. So, in both of those situations, we had a student who came to school and appeared fine at one point, then had a major emotional breakdown. But now that we know them and know what to expect, we're able to kind of - I would not even say circumvent the trauma they experience but give them the support they might need to get through those situations.

However, high school principals' understandings of the underlying causes of a student experiencing trauma were gun violence, student suicide, and students' murder. High school students have more life experiences, such as obtaining employment, driving a car, and having more friends. These life skills can bring adverse experiences and exposure to trauma. Students facing trauma are more chronic as they call forth a range of responses: fear, loss of trust, and a decreased sense of safety (Center for Substance Abuse Treatment, 2014). Two high school principals spoke poignantly regarding the experiences their students faced.

Principal Earwood drew on her students' experiences with trauma. The principal pointed out the different violent incidents. "They have experienced the physical trauma, been abused by someone they know or by their friends physically, being hit. Emotional 
trauma, and I'm talking about emotional trauma from relationships, unhealthy relationships, family issues that have had happened with them. They've experienced trauma from losing others, losing their friends. Not so much losing adults around them, but my kids have many that violent trauma, which ordinary people don't get to associate with. I want to say everyday trauma, but they've got that enhanced...yeah, it's like trauma on steroids."

Principal Myers described the loss stating, "Unfortunately, the loss of four students who lost their lives violently to community trauma and gang violence.” Principal Reed said, "I've lost a ton of kids, unfortunately. You do this job; you lose kids all the time, whether it's a car wreck or something crazy. But to have lost four kids this year, one to suicide, which is some trauma that we probably didn't even realize existed, and then three to murders. We're not talking accident; we're talking murders. I think our kids know; that's where my most significant focus is. Obviously, I need to talk about the whole kid, and we need to discuss trauma and all that, but just this community violence that they deal with when they're outside of school."

All principals reflected on the magnitude of traumas their students were facing. It is the experiences that shaped their behaviors and academics within the school building. The incidents became more violent and aggressive as the students became older. The traumatic experiences are brought into school, and principals must understand trauma and Trauma-Informed Care to provide resources to help students remove the barriers to their learning. 


\section{Infrastructure and leadership}

Principals need to create safe, welcoming, and trauma-sensitive environments for students. Principals must understand how their leadership impacts how trauma is addressed in the school building. Whether they used the term leadership or the phrase supports in place, set the tone, or lead by example, leadership was well-covered. For this research, infrastructure is defined as "the principal's responsibility when addressing trauma within the school building." Principal Dunn shared the principals' responsibility when addressing trauma within the building, stating, "establish culture and climate, kids have to Maslow before they Bloom. By understanding there's a trauma in place, nothing else matters; helping teachers understand the value that putting supports in place to address trauma is equal to academic, professional development for understanding." Principal Gibson felt passionate in stating, "principals have to know their kids. You got to know your kids and know what their trauma is. Our responsibility has got to be to have a finger on the pulse on what your trauma is. Next, it is essential to put in place the right people to wrap around the pulse."

Principals must have a clear understanding of their role in addressing trauma and how Trauma-Informed Care communication is shared with stakeholders. All the principals agreed that stakeholders such as students, staff, parents, and community members affiliated with the school should be aware of how trauma and Trauma-Informed Care are implemented in the building. Principal Earwood said, "we do a good job communicating that to our teachers. I don't think we've communicated that to our students, and I know we haven't communicated well to our other stakeholders. 
Communicate what's available to our stakeholders as it relates to Trauma-Informed Care.” Principals share that teachers receive more trauma training during embedded professional development or faculty meetings. Seven of the fourteen principals stated they did not communicate to parents strategies on how trauma is addressed in the building. Principals discussed using parent messenger and newsletters to communicate with the families; however, no specific information regarding trauma or TraumaInformed Care was shared. Principal Yalden shared why trauma strategies are not communicated to their families. Principal Yalden explained, "I'm careful because I just don't want the negative stigma that sometimes...especially knowing our community, mental health has always been taboo in the Black community. I am careful about how I communicate that. Yeah, I mean, I think some families are coming to grips with it. It is okay to say you need help. But I still think, in large, black families, they do not want you in their business."

Five of the fourteen principals stated strategies are not communicated to students on trauma strategies within the school. Principals acknowledge this as an area of growth and opportunity. The Social-Emotional Director discussed how trauma processes are filtered down to the students as a district. The Social-Emotional Director stated, "I do not think we [as a district] have done an excellent job with communication to kids, "telling them is what trauma is. We all have trauma; no one is exempt from trauma. Of course, I do not know if kindergarten, first grade, and second grade could understand that, but when you start getting into third, fourth and fifth and higher, I think conversations could be had with those kids about what trauma is and what trauma looks like, with our kids. Even with our parents, we have done some trauma training with parents to understand 
what trauma is. We have many trauma-exposed parents raising trauma-exposed children. This whole cycle of how I deal with my trauma plays out in both the kids and the parents. I believe we could probably do a better job with that. I do not think we have gotten to that level yet, because we have not reached all teachers in schools yet." Several principals acknowledge that keeping a connection to trauma is a critical component in the infrastructure as a building principal. Trauma connections must filter down to reach the students. Providing professional development opportunities to learn more tangible resources will help create more practices, procedures, and policies to address trauma.

\section{Professional Development}

Traumas are occurring with our students. The COVID-19 pandemic and social unrest have impacted all students. Principals discussed the need for specific training on trauma and Trauma-Informed Care when students return to brick and mortar buildings. In this study, two schools received TIC training from an outside agency called BOUNCE Louisville. BOUNCE, Building Resilient Children and Families, was created in 2014 by the Foundation for a Healthy Kentucky Investing Kentucky's Future initiative. The BOUNCE coalition provided a three-year relationship in which the school received extensive training on trauma and TIC. The training was embedded in professional development and faculty meetings. Principal Earnhart shared, "When BOUNCE came in to train us on trauma-informed care, understanding what all things are considered trauma, how trauma impacts basic needs, and the adverse childhood experiences (ACEs). We shifted the dynamic and the narrative of what's wrong? What's wrong with you? What is wrong? What are you doing?" Jefferson County Public Schools has a partnership with the University of Kentucky Center on Traum and Children. The District Social-Emotional 
Director and four resource teachers participated in the training presented by the University of Kentucky.

In this study, four schools have completed the TIC training modules facilitated by the district's Social-Emotional Learning Department. Principal Reed stated, "They are still waiting on the district models to train her staff." District Social-Emotional Director acknowledges 49 schools out of 156 have completed the six-hour trauma models facilitated by the district. The modules are taught during embedded professional development and staff meetings. Once the modules are completed, a resource teacher would be the contact person. Also, the District Social-Emotional Director expressed, "one obstacle is that even though we give them [them] these fixed trauma modules, some of them still don't have buy-in; it's like they [teachers] still don't believe that trauma really can impact a student on that level."

\section{District Support}

The principals discussed their perceptions of district support. All acknowledged that an increase in district resources to address trauma and Trauma-Informed Care is warranted to provide appropriate services for our students and program success. Several principals implied the need for more funding for trauma supports. In response, Principal Oakley said financial support is a huge barrier when providing resources for trauma.

Oakley said, "Recently, JCPS has done an excellent job of throwing some money at the problem, but it is not enough. A funding model for mental health counselors is proportional to school size and proportional to school needs, much like the teacher funding model.” In 2019, the district's superintendent made a three million dollar investment in mental health with the hope of boosting student achievement. Each school principal in this study was provided with a full-time or part-time mental health counselor. 
Principal Reed was excited to share that the mental health position has been a phenomenal resource. Principal Yalden explained, "the most important resources provided by the district where the mental health counselor is the person, even if they don't have enough, which I would love to have three. We need it. About a third of our population needs mental health support; they are the point person for community support." Though the principals interviewed acknowledge the benefits of having a mental health counselor, the disproportionality of not having enough support is strongly felt. Several principals mention they must share their mental health counselor with another school. It is essential to give schools resources that fit the population needs of the students in attendance.

Principal Ebanks echoed Principal Oakley when addressing the district's resources, stating, "I'm sure it is a money thing. We need more people to come to support this work. I think that they could do more in coming to your schools and one-stop shopping. It's one time, and they're making some follow-up on their part, but I think they need to commit to some more consistent time. These are subject matter experts; then, they need to be in these buildings more regularly." The District Social-Emotional Director acknowledged the district's barriers when trying to support principals and student needs. The director adds, "I think our main obstacle is there's just not enough of us. Suppose you're trying to spread four people around 156 schools with countless teachers and a hundred thousand students. And it's just not enough of us to, one, get all the training out that we need to. And two, provide the support and resources to our teachers and our principals and our students that we know they need." 


\section{Time}

All principals want to ensure students experiencing trauma get their needs met. They saw Trauma-Informed Care as an opportunity to put resources in place to help families. All the principals shared the same sentiments that having the time to spend on training staff was a huge barrier. Principals are aware of the demands put on themselves and their staff. Principal Clark stated, "The various demands you have in terms of professional development is a barrier. So you only have so much time with the staff. You recognize that there are tremendous needs, competing priorities in terms of instructional need or training for racial equity or training for all the various things that all are equally important, so I would say a barrier is a time to train staff properly.” Principal Oakley declared, "I believe one obstacle has been time. There's never enough time to do TraumaInformed Care, and time includes giving teachers the support and training they need to do that. The time to actually...not implement in the building but the time required to implement it and have it done with fidelity. I think that has been a barrier. We need to have some additional support to give that prescriptive care honestly." Principal Reed added this point, "The student with needs and potential students who have experienced trauma vastly outnumber the building's adults. The time to give the attention needed to each student to allow them space to talk through what's going on with them, I think that is a huge barrier."

The principals shared that having more time to train staff on Trauma-Informed Care practices provides appropriate resources for students experiencing trauma. They also discussed how time could help improve staff relationships with students experiencing trauma. 


\section{Mental Health}

A significant proportion of students are impacted by trauma within the school buildings (e.g., bullying, teacher death). Its influences bring challenges in identifying and addressing traumas student experience. Trauma presents as misbehavior or academic delays as these can be related to attempting to cope with traumatic stress. Traumatic stress reactions can include dissociation, avoidance, intrusion, and hyperarousal. Principals must have a clear understanding of trauma and Trauma-Informed Care to implement strategies to help students who are impacted directly and indirectly by traumatic stress.

\section{Secondary trauma exposure}

Principals shared the recent secondary traumas, which indirectly expose students to trauma from people who have been traumatized themselves. The COVID-19 pandemic had begun spreading like wildfire. At the time of the interviews, Jefferson County had confirmed 392 cases of COVID-19, 13 deaths, 11 patients in ICU, 7 patients on ventilators, and a positivity rate of $8.8 \%$ (Department of Public Health and Wellness, 2020). The Black community, communities of color, poverty, and the homeless were more likely to experience health inequities with COVID-19, leading to a higher death rate. Upon talking with principals, finding out what exposure students were facing expressed the following: stressed parents are losing a job, food shortage, family members' death, quarantine, inequities with technology, and school routines suddenly interrupted.

Principal Yalden reported, "With COVID just talking to our families, I think just the loss of income if they're not essential workers or some were furloughed. So that only caused extra stressors for them as a family, and then consequently to our kids." In March 2020, the governor of Kentucky closed non-life sustaining business to in-person traffic. 
Childcare centers, cosmetologists, independent business owners, playgrounds, basketball courts, group activities, churches, and nonessential retail companies were to close as Kentucky was placed in a state of emergency. Principal Irwin expressed how these secondary traumas impacted her families: "I know we collected probably, I would say, between 30 to 40 food baskets to provide to families. So some of them struggle with getting food. With the whole NTI piece, families struggle with just instruction and technology and only having access to the work and the curriculum." The Kentucky Cabinet for Health and Family Services offered family support through the Pandemic Electronic Benefits Transfer (P-EBT) program. P-EBT provided benefit care for families to purchase food to replace meals missed at schools. Any student who attends a public or private school and is eligible for free or reduced-price meals or attended a school that provides free meals to all students qualified. As more and more families were uprooted from their jobs and forced to stay in place, students had to face their caregivers' traumas.

\section{Parental Engagement}

Often, trauma impacting our students is happening outside of the school building. However, those traumas are brought in to school. Students need parents to be actively involved and connected to the school. Principals often face barriers to engaging parents with the school. Parent support and engagement to assist students' academics and nonacademics are a considerable barrier for many schools. Nine out of the fourteen principals expressed barriers to parental engagement. The terms of parental involvement or parental support were often used to describe parental engagement. For this research, parental engagement is defined as "parents/guardians showing an interest or motivation to participate in the learning process actively." Principal Dunn describes the significance of parental support and the hurdles he faces. He stated, "Honestly, sometimes the most 
significant barrier has to do with the family consent. Typically, a lot of times, trauma has stemmed from the family members. They're still living with them at home. They get frightened that if a child starts receiving support or services. Often afraid and questioning what will that uncover about me as a parent? So I think sometimes parent consent is one of our biggest obstacles to overcome. Mental health or therapy has a negative stigma associated with it. I sometimes guess another obstacle to overcome for us is some cultural barriers. Mental health sometimes is often associated with a very negative stigma, so some of our families are international families."

Principal Irwin described a similar school issue, which led her team to create a social and emotional learning plan with the counselor and the Mental Health Counselor. She stated, "I would say the biggest problem is the denial of the parents. You have parents that you reach out to and ask, we think your child would benefit from working with Centerstone or would benefit from working with our Mental Health Counselor. She has some one-on-one counseling. Counseling, in our community, can be a stigma. So some parents are just against it, and it's frustrating because you know that the kids need help." Principal Earwood shared, "Many times parents don't want outsiders to know what's happening within the home. And so sometimes parents throw up those blockers that, 'this is our business, we're going to take care of it. I don't need anybody else coming in and meddling.' We are here to support you. Not to invade or take from but to help. I just think that message only hasn't been communicated clearly enough.” Overall, during the interviews, principals felt the staff struggled with connectivity and repertoire skills with parental engagement. 
Principals completed the Trauma-Sensitive School Checklist Questionnaire; the questions asked if strategies to involve parents are tailored to meet individual family needs and include flexibility in selecting times and places for meetings, interpreters' availability, and translated materials comparable to interview answers. Three principals stated elements were fully in place; seven principals said elements are mostly in place, and four principals stated elements are partially in place. The majority of the principals have strategies mostly in place to involve and engage parents with meeting students' needs. Principals of students who do not have parental engagement expressed how they exhaust all communication forms to get parents involved in promoting student achievement. Principals Myers shared, "We have a student success team; we can refer students to the team for help. We bring the student in, bring the parent in, and have wraparound meetings, and develop plans for them."

According to the principal's Trauma-Sensitive School Checklist Questionnaire results, they were asked if the staff actively uses a repertoire of skills to engage and build positive relationships with families. Four principals stated elements are entirely in place. Four principal's sated elements are mostly in place. Six principals said elements were partially in place. The questionnaire revealed that eight principals feel staff use their repertoire to build relationships with students. Building positive relationships with families promotes parent engagement and student support to succeed in school (Rossen \& Hull, 2013). Principals scored themselves higher on the questionnaire. However, principals explained that staff did not have robust connectivity and few repertoire skills to engage and build positive relationships with students and families upon asking more detailed questions. Diloreto and Gaines (2016) stated this discrepancy could sometimes 
be the case in that quantitative findings do not result from sufficiently explicit or individualized interrogations by way of a survey. In contrast, qualitative, open-ended questions provide the "room" needed by participants to express or explain their responses (p. 148) sufficiently.

\section{Classroom-Based Academic Strategies}

The elementary and middle schools utilized schoolwide curriculum programs such as Character Strong, Leader in Me, Promoting Alternative Thinking Strategies (PATHS), and Second Steps to provide support to students facing trauma nonacademically. Principal Irwin shared, "Each morning, classes review a PATHS lesson. It focuses on different things like relationship building, self-control, or responsive decision making." The programs promote social and emotional development to address trauma. Three elementary principals mention how they utilize Positive Behavioral Intervention and Supports (PBIS) to provide behavior and social-emotional supports for students schoolwide as a tier-one intervention.

Academically, trauma is difficult for principals to address. Principal Heath said,

"The most challenging part of addressing trauma in academics is grading practices, which philosophically, do not lend themselves to addressing an array of issues, trauma being one of them." Principal Clark shared, "Unfortunately, some damage is done from an academic standpoint before we understand that there was a traumatic event that took place." Principal Dunn echoed these sentiments, stating, "Knowing that academics, yes, and a student may need support. However, I still go back to it because academically, you 
can no longer make an A; you just have some baggage that keeps you from that. So let's go and give you some support socially and emotionally.” Many principals utilize weekly academy or team meetings to review students' grades and data trends to determine if the student is experiencing a traumatic event or struggling with the concepts. All agree tighter practices are needed to address trauma academically.

\section{Staff connectivity with students}

During the interviews, principals understood students experiencing trauma need support from staff to achieve success in school. Nine principals acknowledge that staff buy-in, the most prevalent response, staff mindset, and building trust with staff, posed barriers for students to connect with teachers and the school. The nine principals felt staff struggle with connecting with students. In many instances, they expressed a lack of understanding regarding student trauma, mistaking student trauma as misbehavior, staff not building relationships with students, and students having a lack of trust with staff. Principal Ebanks stated, "The teachers need to change their attitude about how they want to look at the behaviors that kids are experiencing and make that connection to identify that this is not necessarily about me and that some other implications are at play."

Principal Scott, when speaking to staff about student trauma, stated, "We have to be willing to have short memories, and we cannot be out to get a pound of flesh when students are in "trouble." It doesn't help to be punitive. We (principals) must shift staff members' mindset to say that they (students) will need more." Principal Baker shared, "Staff is probably the most in your face barrier within the school. Some staff being uninformed or have a mentality of this is how I was raised, you respect adults, I'm the adult. And you do what I say because I said to do it. But it's not going to work with kids coming from traumatic situations where they already have issues trusting you." 
Principals have to educate staff to see beyond troublesome behaviors or academic barriers to build relationships with students. Principals discussed how staff turnover contributes to disparities. New teachers must learn about the students, families, culture, and climate of the building. Students lack equitable access to veteran teachers who have a foundation and roots in the building and educational experience. The lack of experience and teacher awareness can contribute to the lack of connectivity with students. Educating staff on connectivity and building relationships with students experiencing trauma can help students have successful school experiences.

\section{Non-academic Supports}

Trauma impacts students socially, emotionally, academically, and nonacademically—only one principal mentions a universal screener to recognize and address trauma within the school building. Many principals utilized resources from positive behavior interventions and supports (PBIS), mindfulness, promoting alternative thinking strategies (PATHS), second steps, morning meetings, academy level meetings, and advisory time to implement and address trauma and Trauma-Informed Care practices within the building. In addition to PBIS, other Multi-Tiered Systems of Supports to address non-academic or behavior were following behavior flowcharts, establishing schoolwide expectations, and minimizing punitive consequences.

Principal Earnhart discussed how non-academic supports are addressed within the building. Earnhart shared, "We belong to the compassionate school initiative. We have teachers who teach mindfulness as part of the related arts. They do service projects, 
yoga, and students are strategically placed in there if struggling with anxiety, trauma, or whatever their behavior concerns are.” Principal Yalden shared, “As a compassionate school before we start our day, the compassionate teacher or other administrators lead our students through mindfulness each morning during morning meetings." We will go through about ten minutes of mindfulness each morning. Not every school is labeled as a compassionate school, and some rely on other programs to help teach trauma strategies to help students non-academically.

High schools utilized restorative practices to help provide restoration of harm. Principal Oakley shared how restorative practices are guiding the administration team: "I had my administration team trained in restorative practices. The administrative team focuses on not always looking for a consequence but looking for an antecedent and a root cause. Then, make sure the counseling department understands that they serve as academic counseling and mental health counseling." Principal Reed discusses how the academy model and restorative practices are beneficial when addressing experiencing trauma. Reed shared, "We are a part of the Academies of Louisville; we have broken it up into three smaller learning communities, like basically three schools within a school. There is a standing agenda item on those meetings where we are talking about kids. We discuss supports for students. All of the staff are trained in restorative practices. My security team knows how to ask those vital questions as they are walking down the hallway like, "What happened? What were you thinking?" Not just berating and reprimanding them.”

Also, student success teams are essential to provide wraparound services to students and families. Assistance with basic needs, mental health, job support, or housing 
is an example of wraparound services. Typically included are the counselors, social workers, Family Resource Center Coordinators, and Home School Coordinators. Principal Clark shared experience with them at school: "I am fortunate to have a school psychologist, mental health counselor, youth service center coordinator, and two schoolbased counselors to make-up my core team. They provide mental health support and ensure that our kids' social-emotional concerns are being met."

\section{Policies, Procedures, and Protocols}

There are several barriers and challenges that principals face regarding understanding student trauma and implementing trauma-informed practices. Principals are challenged with providing a safe and inclusive learning environment for students to thrive academically and create opportunities and support for challenges students often face. All principals mentioned several obstacles that cause roadblocks to providing Trauma-Informed Care training to staff to ensure student traumas are understood. When principals completed the Trauma-Sensitive School Checklist Questionnaire and when asked if leadership (including the principal and/or the administrative team) develops and implements a trauma-sensitive action plan, identifies barriers to progress, and evaluates success, three principals stated these elements are entirely in place; eight principals said elements are mostly in place; two principals stated elements are partially in place; one principal stated elements are not at all in place. The results emphasize that the majority of the principals discuss the barriers to implementing Trauma-Informed Care within their building. 


\section{Protocols}

I asked each principal about the practices, procedures, and policies that address trauma within their school building. For this research, practices were defined as unwritten tasks or expectations performed regularly. For example, each teacher must greet the student at the door. Procedures were defined as an established or official written actions that are conducted in a specific order. For example, a substitute teacher can walk into any classroom and follow the procedure step-by-step. A fire drill procedure was used as an example. Policies were defined as principles and bylaws that address trauma and TraumaInformed Care adopted by the Site-Based Decision Making (SBDM) committee. The results of the Trauma-Sensitive School Checklist Questionnaire yield principals were asked if policies describe how, when, and where to refer families for mental health supports; and staff actively facilitate and follow through in supporting families' access to trauma-competent mental health; four principals ranked elements as fully in place; six principals ranked elements as mostly in place; four principals ranked elements as partially in place.

Interestingly, principals scored themselves high on having policies partly in place or entirely in place. Yet, during the interview, no principal has specific Trauma-Informed Care policies written within the SBDM bylaws. The discrepancy between the TraumaSensitive School Checklist Questionnaire is evident. The Questionnaire gauges principals' perceptions of what they believe the practices, procedures, and policies around trauma and Trauma-Informed Care are within their school. The Questionnaire helped develop interview questions to seek principals' understanding of trauma and TraumaInformed Care within their schools' practices, procedures, and policies. Principals may have the desirability and perception to achieve a trauma-sensitive school; however, 
understanding practices, procedures, and policies regarding trauma are foundational when creating a trauma-sensitive school.

Principals often combined practices, procedures, and policies into one category. Principals couple trauma and Trauma-Informed Care policies with bullying, safety, and behavior policies. Principal Steward stated, "I don't think we have one that talks explicitly about Trauma-Informed Care. We have some programs that are in place. When I think about the SBDM policies, we have some that focus on wellness." Principal Dunn felt, "Policies are written when things don't occur because of procedures and practices." Principal Oakley stated, "We have what JCPS has as the standard policies on how to adapt and answer those [practices regarding trauma]. They mostly live in the counseling office. We do not have anything specific that says this is how an educator will, how they will necessarily approach that. I don't know what that looks like. I've thought about that over the last couple of years, but it's challenging to have a one size fits all way to approach this. I think it's probably better that it lives and stays in the counseling office rather than it becomes necessarily a process flow chart. I may be wrong. I'm not the expert on that, but I've yet to see something that would be a useful process flow chart that I could roll out to 150 staff members."

Trauma-Informed Care policies do not exist at the school level for the principals in this study nor at the district level. The District Social-Emotional Director stated, "Within the student handbook that we pass out every year from the Culture and Climate Department; it has a section about trauma-informed practices and the district's resources as far as trauma." JCPS district does have a Racial Equity Policy; however, trauma and Trauma-Informed Care are not addressed within the current guidelines. Three principals 
have procedures in place to address trauma and trauma-informed care. Principal Earnhart explained, "Our counselor has worked with our school social worker, Centerstone therapist, and mental health counselor to develop what specific steps are taken when a kid or family needs support for trauma and emotional support."

Principal Myers shared how the student success team is utilized in the building to address trauma and trauma-informed care. Principal Myers noted, "Procedures are presented at the beginning of the year to continue to remind staff of them. They are reviewed in the academy meeting on the referral process. We bring in students, parents, and we have wraparound meetings, and we develop plans for them. Also, we have one person on the student success team responsible for attending every academy meeting. By attending the meeting and hearing the conversations, we can communicate with teachers to help the student." The three principals with trauma procedures utilize screeners to help identify students who are experiencing trauma.

Principal Dunn discussed how they utilize the Student Risk Screening Scale (SRSS) Drummond screener instrument as a procedure to measure internal and external behavior. The SRSS screener tool helps identify at-risk students for tier prevention intervention. Principal Dunn shared, "We are a very data-driven school. We have developed a modified Drummond instrument. We have modified it a little bit to take some of the academic pieces out and just get to the internal and external behaviors. Teachers will go through and will three times a year rate kids. Often, before implementing the screener, those quiet kids who don't get into trouble, don't call attention to themselves, they would slide under the radar. This has allowed us to really identify kiddos who are internalizing behaviors. Teachers have clear instructions on completing 
the screener and how to refer a student for services." Many principals have practices that are implemented to address trauma.

Principal Baker expressed how her school utilized temperature checks on kids as they walk in the building. Staff are assigned at intersections, where kids come from different places; they greet kids and monitor students' body language. Principal Baker shared, "We have some that come in crying more days than not, and I can grab them right there as soon as they come in, talk with them and love on them, and get them in the right headspace to start learning for the day." As the principal's understanding of trauma grows, these proactive practices create a trauma-sensitive school's foundation and benefit every student.

\section{Chapter Summary}

Our students are experiencing trauma, and it is playing out during a pandemic, virtual learning, and racial unrest. Principals must have a clear understanding of trauma and trauma-informed care. The coding of the data collected allowed for intimate examinations and synthesis of the high need index principals' lived experiences working with students experiencing trauma. The Flexible Framework was used to review the findings. In the next chapter, conclusions will be drawn from the findings and implications for research and practice. 


\section{CHAPTER V CONCLUSIONS}

\section{Introduction}

In this final chapter of this phenomenological study, I present the study's summary, discussion of the findings, policy implications, implications for practice, recommendations for future research, and conclusions. This study will provide new insight into understanding and executing Trauma-Informed Care (TIC) for students experiencing trauma in high Need Index (NI) schools.

\section{Summary of the Study}

My research explored principals' experiences and perspectives of trauma and Trauma-Informed Care in high Need Index schools within a large urban school district. The Flexible Framework (FF) set the direction of this research study. The Flexible Framework is a systemic overview of school operations and provides a process for reviewing a school's impact on student success (Cole et al., 2005). It has three essential functions (a) make sure that identified initiatives are executed effectively; (b) integrate all the individual action steps that make up an initiative to ensure they are all working in harmony; (c) ensure that all initiatives undertaken are working together to create a trauma-sensitive school ecology (Rossen \& Hull, 2013). This Framework serves as the 
anchor for understanding the findings in this study related to the core of trauma and Trauma-Informed Care ideology.

There are limited studies that examined the principals' perceptions and understandings of Trauma-Informed Care. Previous research has focused primarily on teachers perspectives (Anderson, Blitz, \& Saastamoinen, 2015; Baweja et al., 2016; Green, Xuan, Kwong, Holt, \& Comer, 2016; Mendelson, Tandon, O'Brennan, Leaf, \& Ialongo, 2015; Osagiede et al., 2018; Perry \& Daniels, 2016; Whitaker et al., 2019). This study builds on the analysis of Walkely and Cox (2013), which emphasized the notion that a "commitment to adopting a trauma-informed approach will require the full support and commitment of the leadership at each school, starting with the principal and co-principal" (p.125). Rossen and Hall (2013) discuss the importance of principal leadership being the most important predictor of quality implementation for whole-school reform. This study was conducted during a pivotal time in education - COVID-19 pandemic, non-traditional virtual instruction, and racial unrest from the murder of Breonna Taylor were happening in the city of the study. Principals must fully attend to the trauma that has occurred - even from a distance.

My research focused on examining the K-12 principals' perceptions of trauma, how they address students experiencing trauma, and how they utilize trauma-informed practices to remove barriers students face during trauma in high Need Index schools. To further explore these perspectives of principals' in high need index schools, this study adopts principals responses to trauma utilizing phenomenology methodology and the flexible framework; the following research questions were posed: 
- What understanding do high Need Index school principals have concerning student trauma?

- What are the high Need Index principals' perceptions of potential strategies that could be implemented to address student trauma within existing schoolwide practices?

- What are the high Need Index principals' perceptions of whether the TraumaInformed Care practices achieve their intended purpose(s), and what do they recommend for the future?

\section{Research Design Summary}

This study was conducted in the Jefferson County Public Schools district. It is the largest urban school district located in the southeastern part of the United States. This public educational institution serves approximately 100,000 students from kindergarten through twelfth grade. In early 2020, the district suddenly had to cease traditional brickand-mortar instruction due to the coronavirus (COVID-19) pandemic. According to the World Health Organization, COVID-19 is a new virus that may cause respiratory infections transmitted through respiratory droplets through direct contact of an infected individual. This virus was unknown before the outbreak began in Wuhan, China, in December 2019. It is now a pandemic affecting countries globally.

The Kentucky Department of Public Health (KDPH) reported the first detected case of COVID-19 in a Kentucky resident on March 6, 2020. The governor of Kentucky recommended that all school superintendents cease in-person classes for an extended period to decrease community transmission. The district launched its first online and 
virtual learning platform called Non-Traditional Instruction or NTI 1.0. Face-to-face instruction ceased, and students quickly transitioned to online platforms. The sizeable urban district experienced a digital divide, with some students not having adequate or needed resources to participate in the new forum. The district offered a limited number of Chromebooks and hotspots for students who did not have computer access. These technology inequities were among the many barriers students and families were facing at the time of the study.

As Kentucky students were experiencing vast disparities with technology, widespread job, income loss, and food insecurities, the city of Louisville would receive worldwide exposure following the murder of Breonna Taylor. This 26-year-old medical emergency response technician was shot and killed in her apartment by police officers in March 2020. Six months after the murder, the grand jury indicted one officer on wanton endangerment, and the other two officers face no indictments. The city experienced protests and uprising due to social injustice and racial unrest in this case. School principals were facing extraordinarily unusual circumstances with students, families, and staff.

The interviews for this study occurred in June 2020 as principals were ending the school year. Principals all expressed their lived experiences of students with trauma during the present time and reflected on occasions during the school year. Fourteen principals and one district social-emotional learning director participated in the virtual interviews. Before the talks, the principals completed the Trauma-Sensitive Checklist Questionnaire to gauge how trauma and Trauma-Informed Care are addressed within their schools. 


\section{Discussion of the Research Finding}

Schools play an essential role in providing a supportive and caring environment. Therefore, principals must understand trauma and implement Trauma-Informed Care practices, procedures, and policies to become a trauma-sensitive school. This study's participants are principals of high Need Index schools that high service populations of free and reduced-price lunch, English Language Learners, mobility students, and Exceptional Child Education students. This study utilizes the six themes derived from the Flexible Framework: infrastructure and leadership; professional development; the role of mental health; classroom-based academic strategies non-academic strategies, and policies, procedures, and protocols. The following discusses how each of these flexible framework themes applies to the study's principals' experiences and perspectives.

\section{Infrastructure and Leadership}

Principals must be committed to the process of creating trauma-sensitive environments. Rossen and Hall (2013) stated that administrators' direct engagement is central to the commitment to fully engaging and implementing trauma-informed practices (rather than merely assigning a task force or workgroup). It includes "direct participation in strategic planning, working with staff to identify needs and opportunities for growth, and keeping the vision of a safe and supportive school alive within the school's hectic day-to-day work" (p.256). Devaney, O'Brien, Resnik, Kesiter, and Weissberg (2006) noted principal leadership as the single most important predictor of quality 
implementation for whole-school reform. Principal Steward added to that sentiment of principal's responsibilities and explained, "I think my responsibility, me as a leader of the building, as the instructional leader, is first off, we got to know our stakeholders. We have to know our teachers. We got to know our students. We have to know our parents, and we have to know our community. Because I think with the community, we know the resources we can offer to our parents, family members, and students' resources for our teachers. I think that's probably the main thing and then sharing the message to the teachers." Principals should have fluid communication with all stakeholders on how trauma and trauma-informed care are integrated into the school community.

In this study, seven of the fourteen principals stated they did not communicate to parents strategies on how trauma is addressed in the building. It is important to note several principals referenced technology applications used to contact parents; none of the communication specifically addressed trauma or trauma-informed techniques or practices within the building. Soma and Allen (2017) confirm and acknowledged "school principals can play a central role in shaping school climate and facilitating parent engagement in child learning through their leadership style, communication, attitudes and expectations" (p.119). When incorporating trauma-informed care practices into the school infrastructure, the principals acknowledged that all stakeholders should have input to ensure they achieve their intended purposes. Nonetheless, most of the principals in this study did not communicate with students or families, or stakeholders regarding how trauma is addressed in the school. Principals could have the mindset that they are communicating with a parent. Yet, upon reflecting on the practices, these stakeholders 
could foster a stronger connection with the school and build a combined effort to help their students experiencing trauma.

\section{Professional Development}

The theme of professional development was prevalent throughout the narratives shared by the principals. According to Rossen \& Hull (2013), professional development should cover three primary areas. First, it is the strengthening of relationships between children and adults by emphasizing the vital role that staff can play as caring adults in the child's life. Nine principals acknowledge that staff buy-in's most prevalent response, staff mindset, and building trust with staff posed barriers for students to connect with teachers and the school. The principals shared that they felt there was a lack of understanding regarding students who experience trauma; often, the trauma is mistaken for misbehavior, staff not taking the time to build relationships, and therefore students do not trust the teachers or school staff. As depicted in Chapter Two, Penner and Wallin's (2012) study, teachers who build positive relationships could influence students' reactions to traumatic exposure.

The second area of need for professional development includes developing skills and sharing strategies among educators to help students modulate their emotions and gain social and academic competence (Rossen \& Hull, 2013, p.257). The trauma-sensitive checklist questionnaire revealed eight of the fourteen principals felt staff had a repertoire of skills to engage and build relationships with students. However, upon taking a deeper dive into the interview, I learned principals struggled to get staff to share strategies due to staff turnover. Traditionally, high need or high priority schools tend to struggle with teacher attrition. When veterans are unavailable to help new teacher teachers facilitate 
strategies centered around assisting students in modulating, their emotions are repeated and not retained due to teacher retention.

I found a discrepancy with the first area of professional development. During the interviews, nine principals acknowledged staff posed obstacles to build relationships and connect with students. On the other hand, in the trauma checklist questionnaire, eight of the fourteen principals felt their staff had a repertoire of skills to engage and build relationships with students.

Table 3.

Trauma-Sensitive School Checklist Questionnaire and Flexible Framework Alignment

\begin{tabular}{|c|c|c|c|}
\hline College & $\begin{array}{l}\text { Questionnaire } \\
\text { Response }\end{array}$ & Interview Response & School \\
\hline Principal Ebanks & Mostly in place & $\begin{array}{l}\text { Teachers need to change their } \\
\text { attitude about how they want to } \\
\text { look at the behaviors that kids are } \\
\text { experiencing and making that } \\
\text { connection to identify that this is } \\
\text { not necessarily about me and that } \\
\text { some other implications are at } \\
\text { play. }\end{array}$ & $\begin{array}{l}\text { Red } \\
\text { Maple }\end{array}$ \\
\hline Principal Scott & Fully in place & $\begin{array}{l}\text { Teachers need to be we have to } \\
\text { be willing to have short } \\
\text { memories, and we cannot be out } \\
\text { to get a pound of flesh when } \\
\text { students are in "trouble." It } \\
\text { doesn't help to be punitive. We } \\
\text { (principals) must shift staff } \\
\text { members' mindset to say that they } \\
\text { (students) will need more. }\end{array}$ & Gardenia \\
\hline
\end{tabular}

The study completed by Diloreto and Gaines (2016) supports the notion that qualitative questioning allowed for more in-depth insight and explanation, yet survey questionnaires only allow for selected answers. In this study, the trauma-sensitive checklist 
questionnaire only allows four chosen responses. Principals scored themselves higher on the questionnaire compared to the one-on-one interview questioning.

Rossen and Hull (2013) stated the third area should focus on identifying and using outside supports to help students become successful and see school value (p. 258). As Principal Ebanks and Principal Oakley expressed, more staff, training, and resources are needed to effectively support trauma and trauma-informed initiatives. The District SocialEmotional Director noted a similar concern. With limited resources teachers, the department is spread too thin to support a district of this magnitude. The District Social Emotional Director reported, "We must first lay that foundation of being traumainformed, but everything is a funding issue, everything is a funding issue. With the pandemic, our district asks [community stakeholders] for seven and half more stimulus as far as tax, tax increases. I really don't see them adding more people to my department to do that." As of October 2020, Jefferson Circuit Judge Brian Edwards approved the property tax increase stating the petition contained required numbers of valid signatures required for approval. Jefferson County Public Schools is projected to receive $\$ 54$ million to reduce the achievement gap. I believe the funding increase could provide additional resources to address trauma-informed care disparities in our district. Our students, families, and staff have been affected by the trauma associated with the pandemic.

Amid the COVID-19 pandemic and social injustice currently happening within the city becomes more prevalent, more students will experience trauma. More training will be needed to help principals and staff understand the significance of their role as caring adults in the lives of traumatized children who are seeking support in this current 
virtual learning (Cole, 2005). The principals recognized the importance of traumainformed care training; however, there is no time to complete additional training. Two principals participated in trauma-informed training facilitated by BOUNCE, and four principals participated in the district's trauma training. The BOUNCE agency provided a three-year partnership with at least one person assigned to your school. This person was readily available to the principals and schools. The district program is not equipped with the human resources to effectively give the schools the accessibility needed to implement trauma-informed programs. Principal Clark, Principal, Principal Oakley, and Principal Reed all declared students experiencing trauma vastly outnumber personnel. Due to the district's demands on other professional development and training initiatives, traumainform care training does not negate priority status.

Trauma-informed care training helps educators understand the significance of the adverse childhood experience brought into the school building (Felitti et al.,1998 and Blodgett \& Lanigan, 2018). In chapter two, the updated ACEs study conducted by Blodgett and Lanigan (2018) discussed building principals benefited from learning about how trauma impacts student's academics, behavior, and attendance factors within schools. The lack of support and lack of time available for training to improve school practices to address student trauma cannot be implemented unless the district provides additional resources. When schools are trauma-informed, research indicates the following improvements: academic achievement and test scores, school climate, teacher sense of satisfaction and retention, graduation rates, and community and family collaboration (Chafeouleas et al., 2016 and Soma \& Allen, 2017). Also, trauma-informed schools see a reduction in student behavioral outbursts and referrals, stress for staff and students, 
absences, detention, suspensions, student bullying, harassment, and fights, need for special education services and classes, etc. drop-out rated (Chafeouleas et al., 2016 and Soma \& Allen, 2017). Principals recognize the need for trauma-informed professional development in our to better the practices within their schools.

\section{Mental Health}

According to Cole (2005), a "mental health professional with expertise in trauma can offer many kinds of assistance to schools helping traumatized children learn" (p. 58). All principals reflected on the magnitude of students' traumatic experiences within their buildings; the incidents became more violent and aggressive as the students become older. Mental Health Practitioners can help principals and staff address the traumas students are experiencing. In 2019, Jefferson County Public School Superintendent invested three million in having mental health practitioners added to each school. However, the principals communicated that this was not enough. Several principals shared the mental health practitioners are often shared with another school. Principals felt mental health practitioners should be assigned based on the unique needs within the building. Principal Dunn explained, "I serve a very high population of English Learner students; with so many kids and so many needs, with almost 600 kids, it would be beneficial to have the resources at the beginning of the school year. We have one counselor, a part-time mental health counselor, so we have many more needs than personnel. We have an outside therapist with Centerstone, who is full-time. However, her caseload maxes out every year by Christmas." Many principals would like to see more mental health professionals at school and staff to receive more training to become more trauma-sensitive. 
Cole (2005) encourage school-based mental health professionals to be involved in leadership teams and training programs. The need for this is demonstrated in some of the principal's student success teams. One of the significant barriers principals share is parent engagement. Principal Clark and Principal Heath shared how the student success team has helped with parent engagement and felt competent in their abilities to meet the obstacles and hardships they are presented with to help students experiencing trauma. The student success team can provide wraparound services for families. However, if the mental health practitioner is not full-time at school, this poses additional challenges.

\section{Classroom-Based Academic Strategies}

All principals in this study recognized the difficulty of addressing and identify

when students are experiencing academic trauma. This theme looks specifically at trauma responses to behavior. Rossen and Hull (2013) identified students experiencing trauma may be difficult to identify in a classroom because many students have learning profiles that are similar to students with disabilities (e.g., learning disability, attentiondeficit/hyperactivity disorder [ADHD], emotional disturbance), while some exhibit no discernable issues in the classroom (p.259). The principals acknowledge trauma as a secondary response to behavior. Many principals referenced students who experienced traumatic events tend to be more aggressive. One of the noticeable similarities in the results of this study, students exposed to traumatic events displayed more how aggressive behaviors such as fighting, anger outburst, and impulsiveness (Busby, Lambert, \& Ialongo (2013); Blevins et al. (2015); Souers and Hall (2017).

Cole (2005) suggested consistency in classroom expectations, written plans, positive behavioral supports, nonverbal cues, and providing safe environment strategies 
when implementing a trauma-sensitive class-based system. Elementary and Middle schools referenced the Compassionate Schools and Positive Behavioral Intervention and Support programs to utilize classroom and school-wide structures to address trauma. Elementary principals described calm down areas, mindfulness hours, and classroom guidance to address classroom strategies. Middle and High Schools utilized restorative practices to restore harm and eliminate the in-school student suspension (ISAP) room.

However, eight principals referenced the inconsistencies in classroom strategies and practices to address trauma. Inconsistencies lead teachers to write more behavioral referrals leading to more principals to assign punitive punishment and suspensions. Establishing classroom-based and school-wide trauma strategies will lead to less disciplinary punishment (Cole et al., 2005; Mader, 2019; Wolpow et al., 2009). In addition, students have more social and emotional supports.

\section{Non-academic Strategies}

One of the most impactful ways to help traumatized students are establishing relationships (Cole, 2005). Rossen and Hull (2013) agree, stating, "for many students impacted by traumatic experiences, relationships with even one adult in school can foster a sense of safety, improve student engagement and social success, and increase student attention and achievement. Often these relationships are easier built around non-academic issues, as often the student impacted by traumatic experience will struggle to be successful with academic material and associate academics with negative emotions" (p.259). Principals voiced the counselors, and mental health counselors are often head any non-academic strategies within the building. Although the school counselor plays a vital role in a non-academic system, the principal must be aware of the design, fluid on 
the implementation of the strategies, and ensure practices are whole-school approach (Rossen and Hull, 2013) to later creating systemic procedures on how to address behavior in regards to trauma.

Many principals utilize weekly academy and team meetings to review student academic data. When the principals meet with the teachers during these meetings, they can often begin looking for trends and troubleshoots to determine when the changes started. Interventions and academy team meetings provide a supportive environment, as described in Perry (2001), West et al. (2014), and Voisin's (2011) studies. Rossen and Hull (2013) suggest supporting instruction with social and emotional skills. Elementary and Middle Principals utilize social-emotional learning curriculums to address mindfulness, self-awareness, and relaxation practices. Principal Irwin mentioned how the social-emotional strategies are implemented in their school-wide morning meeting. The Social-emotional learning curriculum can support a student's academic and non-academic processes.

\section{Policies, Procedures, and Protocols}

Policies, procedures, and protocols can be observed in school cultures (Rossen \& Hull, 2013). For this research, protocols are referenced as "practices." The federal Substance Abuse and Mental Health Service Administration recommends incorporating trauma awareness and trauma-informed practices within schools. The Massachusetts Advocates for Children (MAC) and Harvard Law School are the pioneers of creating practices, procedures, and policies regarding trauma and Trauma-Informed Care for schools to model. The partnership between MAC and Harvard Law began the Trauma and Learning Policy Initiative (TLPI). In chapter II, TLPI advocates for schoolwide 
trauma practices, procedures, and policies to be apart of the regular school day to have a safe and supportive environment for students ((Trauma and Learning Policy Initiative, 2000). Principals must review their practices, procedures, and protocols to ensure they are trauma-sensitive.

Although there is a clear distinction between practices, procedures, and policies, principals in this study lumped them into one category. None of the principals have schoolwide policies to address trauma. The principals made statements such as "our policies are within counselors' office," "We have an equity policy," "We have a safety policy." "We have a bully policy." When explicitly asked if trauma or Trauma-Informed Care was addressed, all principals stated "no." Rossen and Hull (2013) state practice, procedures, and policies are best observed in the school culture.

Elementary and middle school principals utilized positive behavior interventions and supports (PBIS), mindfulness, and other research-based programs. High school principals used restorative practices to address trauma and behaviors. The issues of disconnection to trauma and Trauma-Informed Care centers around the inconsistency of implementing the practices, having written procedures for accountability purposes, and policies to support providing a safe environment schoolwide. Rossen and Hull (2013) suggest practices, procedures, and policies be reviewed in communication, compliance, collaboration, and community to ensure that trauma and TIC are addressed equitably. Many principals felt TIC is a priority; however, it was not enough time to address it or not enough resources provided to support it. 


\section{Implication for Future Practice}

Principals play an essential role in creating a safe and supportive environment for students exposed to a traumatic experience. However, principals need additional supports to effectively implement trauma-informed practices, procedures, and policies with their schools. Principals need to create a culture of trauma-sensitive within the school. Students are being exposed to and experiencing new traumas daily. This study took place during a global pandemic, virtual learning, and racial unrest due to Brianna Taylor's murder. Many principals were not prepared for the changes that occurred due to these traumas. Principals also voiced their opinions on what future practices would be beneficial.

The results of this study suggest all schools participate in trauma-informed training. First, every school should have Trauma-Informed Care training. Also, every school should be required to complete the Trauma-Sensitive School Checklist Questionnaire and provide results to the district. The Trauma-Sensitive Checklist Questionnaire will provide data and help address that is not fully implemented. This research can offer school principals and district officials first-hand reflections on current practices within the district. This research seeks to provide school principals and district officials a way to remove barriers to ensure trauma and Trauma-Informed Care practices are understood, implemented, and support the students in our district. The questionnaire information will allow for consistent training and modifications in training if needed to support schools. We need to evaluate how we are providing trauma training within our schools. Many principals felt their training should be robust and not just PowerPoint presentations. Currently, the district facilitates training modules during a staff meeting 
after school or embedded in professional development during the school day. Perhaps trauma could include a district-wide institute to provide supports to schools on trauma.

Second, the district should follow the model implemented by the District's Racial Equity Team. The Racial Equity Team has enough resources to provide schools with a contact person. Ideally, the trauma resource teacher will be assigned to four schools to facilitate training and help schools. Currently, there are four trauma resource teachers assigned to service 156 schools. With the recent tax increase approval, a portion of the funding can be appointed to fund more resource teachers and schools' training materials. Schools will experience quality training and instruction and the "sit and get" practice. The resource teachers could also ensure trauma training reaches the student level by helping teachers with classroom-based and non-academic strategies, as mentioned in the flexible framework.

Third, the student's voice is critical. Presently, all students in Louisville are experiencing the pandemic and racial unrest in the city. By forming a trauma committee and including student voices, perhaps they can specifically address what concerns or needs to address trauma from student perspectives. Principals could use their influences to create more practices, procedures, and policies, reaching the students on their level.

\section{Implication for Future Policy}

In 2018, Jefferson County Public School inducted Racial Equity Policy to improve students' outcomes, particularly those who are systematically marginalized and disproportionately represented in the district (Racial Equity Principal Handbook, 2018). The racial equity policy tenets include access, curriculum, staffing, school culture, and 
climate, and central office plan. Superintendent Dr. Marty Pollio has instituted three key pillars to guide our district's practices, the backpack of success skills, racial equity, and culture and climate.

Students are disproportionately experiencing trauma. My research was conducted in the district, leading districts with a racial equity policy to support marginalized and disproportionately students. These same students are experiencing trauma, which is impacting their academic achievement, social-emotionally, and behaviorally. Currently, racial equity does not address student trauma. I would suggest creating a new policy to address trauma or amend the current racial equity policy to add trauma and traumainformed care. Each school is required to have a racial equity committee to discuss equity practices. With the addition of trauma and trauma-informed care committees, all students will have equity treatment regarding trauma.

\section{Recommendations for Future Research}

This study attempted to understand principals' perceptions of trauma and traumainformed care in Jefferson County Public School. This study specifically reported perceptions of the high need index principal's experiences in a large urban school district as they address the practices, procedures, and trauma policies within their schools. As a result of this study, the following recommendation would help scholars continue the research initiated in this study.

Some potential suggestions and recommendations are identified below:

1. Conductive this research in a traditional school year. 
2. Conduct quantitative analysis of the information collected in the study to aggregate the date multiple levels and to provide thicker descriptors

3. Conduct interview with other principals who are not high need index school within the district to identify in the study to determine if their experience and understanding of trauma-informed care practices, procedures, and policies

4. Interview with the stakeholders who are assigned to the schools

5. Conduct research on principals perspectives on trauma-informed care in rural school districts during the same period

\section{Summary}

Students are coming into school buildings carrying trauma that can impact them academically, socially, emotionally, and physically. Principals must have a clear understanding and knowledge of trauma, address students experiencing trauma, and utilize trauma-informed care practices to remove barriers to trauma in high need index schools. This qualitative study explored fourteen high need index principal perspectives of trauma and how they utilize practices, procedures, and policies within their schoolhouses. Unfortunately, principals were forced to address how they implement trauma practices due to the COVID-10 pandemic.

Hopefully, the fourteen principals' experiences can impact the district's change by sharing their perceptions and experiences. While the efforts to increase trauma-informed care training have increased media attention amidst the pandemic, we should never forget the students who experience trauma before the pandemic and the new traumas recently developed. The principals' willingness and cooperation in sharing their perspectives and 
experiences through this dissertation provided an avenue and awareness to a part of educational history that is just beginning to get the attention it deserves. 


\section{REFERENCES}

Allen, M. (2017). The sage encyclopedia of communication research methods(Vols. 1-4). Thousand Oaks, CA: SAGE Publications, Inc doi: 10.4135/978148338141.

Anderson, E., Blitz, L., \& Saastamoinen, M. (2015). Exploring a school-university model for professional development with classroom staff: Teaching trauma-informed approaches. School Community Journal, 25(2), 113-134.

Barrett, S., Eber, L., \& Weist, M. (2013). Advancing education effectiveness: Interconnecting school mental health and school-wide positive behavior support. OSEP Center for Positive Behavioral Interventions and Supports.

Baweja, S., Santiago, C., Vona, P., Pears, G., Langley, A., \& Kataoka, S. (2016). Improving implementation of a school-based program for traumatized students: Identifying factors that promote teacher support and collaboration. School Mental Health: A Multidisciplinary Research and Practice Journal,8(1), 120-131. doi:10.1007/s12310-015-9170-z

Blevins, C. E., Wusik, M. F., Sullivan, C. P., Jones, R. T., \& Hughes, M. (2016). Do negative changes in worldview mediate links between mass trauma and reckless behavior? a longitudinal exploratory study. Community Mental Health Journal, 52(1), 10-17. https://doi-org.echo.louisville.edu/10.1007/s10597-015-9906-0

Blitz, L., Anderson, E., \& Saastamoinen, M. (2016). Assessing perceptions of culture and trauma in an elementary school: Informing a model for culturally responsive trauma-informed schools. The Urban Review: Issues and Ideas in Public Education,48(4), 520-542. doi:10.1007/s11256-016-0366-9

Blodgett, C., \& Lanigan, J. (2018). The association between adverse childhood experience (ace) and school success in elementary school children. School Psychology Quarterly: The Official Journal of the Division of School Psychology, American Psychological Association,33(1), 137-146. doi:10.1037/spq0000256 
Bloomberg, L. D., \& Volpe, M. (2012). Completing Your Qualitative Dissertation: A Road Map From Beginning to End: A Road Map From Beginning to End: SAGE Publications.

BOUNCE Kentucky. https://www.bouncelouisville.org/about1-c1x1t

Bruns EJ, Walrath C, Glass-Siegel M, Weist MD. Schoolbased mental health services in Baltimore: association with school climate and special education referrals. Behav Modif . 2004;28(4):491-513.

Busby DR, Lambert SF, Ialongo NS. Psychological symptoms linking exposure to community violence and academic functioning in African American adolescents. J Youth Adolesc. 2013;42(2):250-262.

Center for Substance Abuse Treatment (U.S.). (2014). Trauma-informed care in behavioral health services: A treatment improvement protocol(Tip, 57).

Rockville, MD: U.S. Department of Health and Human Services, Substance Abuse and Mental Health Services Administration, Center for Substance Abuse Treatment. (2014). Retrieved June 08, 2019, from https://www.ncbi.nlm.nih.gov/books/NBK207201/

Chak, A. (2010). Adult response to children's exploratory behaviors: An exploratory study. Early Child Development and Care, 180(5), 633-646. dx.doi.org/10.1080/03004430802181965.

Chafouleas,S., Johnson, A., Overstreet, S. \& Santoas, N. (2016). Toward a blueprint for Trauma-infomred service delivery in schools. School Mental Health, 8:144-162.

Cole, S., O`Brien, J., Gadd, M., Ristuccia, J., Wallace, D., \& Gregory, M. J. B., MA: Massachusetts Advocates for Children. (2005). Helping traumatized children learn: A report and policy agenda: Supportive school environments for children traumatized by family violence. Retrieved from https://traumasensitiveschools.org/wp-content/uploads/2013/06/HelpingTraumatized-Children-Learn.pdf

Cook, A., Blaustein, M., Spinazzola, J., \& Van Der Kolk, B. (2017). Complex Trauma in Children and Adolescents. The National Child Traumatic Stress Network, 35(5), 390-398.

Creswell, J. W. (2014). Research design: Qualitative, quantitative, and mixed methods approaches. Los Angeles, CA: Sage.

Creswell, J. W., \& Poth, C. N. (2018). Qualitative inquiry \& research design: Choosing among five approaches. 
Crosby, S. (2015). An ecological perspective on emerging trauma-informed teaching practices. Children \& Schools, 37(4), 223-230.

Diloreto, Melanie \& Gaines, Trudi. (2016). An Investigation of Discrepancies between Qualitative and Quantitative Findings in Survey Research. International Journal of Learning, Teaching and Educational Research. 15. 145-154.

Dube, S. (2018). Continuing conversations about adverse childhood experiences (aces) screening: A public health perspective. Child Abuse \& Neglect, 85, 180-184. doi:10.1016/j.chiabu.2018.03.007

Durlak, J. A., Weissberg, R. P., Dymnicki, A. B., Taylor, R. D., \& Schellinger, K. B., (2011). The impact of enhancing students' social and emotional learning: A metaanalysis of school-based universal interventions. Child Development, 82, 405-432.

Dutil, S. (2020). Dismantling the school-to-prison pipeline: a trauma-informed, critical race perspective on school discipline. Children \& Schools, 42(3), 171-178. https://doi.org/10.1093/cs/cdaa016

Felitti, V., Anda, R., Nordenberg, D., Williamson, D., Spitz, A., Edwards, V., . . Marks, J. (1998). Relationship of childhood abuse and household dysfunction to many of the leading causes of death in adults. American Journal of Preventive Medicine, 14(4), 245-258. doi:10.1016/S0749-3797(98)00017-8

Fereday, J., \& Muir-Cochrane, E. (2006). Demonstrating Rigor Using Thematic Analysis: A Hybrid Approach of Inductive and Deductive Coding and Theme Development. International Journal of Qualitative Methods, 80 92. https://doi.org/10.1177/160940690600500107

Green, J., Xuan, Z., Kwong, L., Holt, M., \& Comer, J. (2016). Teachers' reports of outreach to school-based providers of mental health services following the 2013 boston marathon attack. Children \& Schools, 38(4), 227-234.

Grevstad, J. (2007) Adverse childhood experiences in juvenile justice - Pierce County, WA. $\mathrm{Pa}$

Hamoudi, A., Murray, D. W., Sorensen, L., \& Fontaine, A. (2015). Self-regulation and toxic stress: A review of ecological, biological, and developmental studies of selfregulation and stress. In OPRE report\# 2015-30: Office of Planning, Research and Evaluation, Administration for Children

Hillis, S., Mercy, J., Amobi, A., \& Kress, H. (2016). Global prevalence of past-year violence against children: a systematic review and minimum estimates.

Pediatrics, 137(3), 1-15. 
Iachini, A., Petiwala, A., \& DeHart, D. (2016). Examining adverse childhood experiences among students repeating the ninth grade: Implications for school dropout prevention. Children \& Schools, 38(4), 218-227. doi:10.1093/cs/cdw029

Immerfall, S., MEd, RN, BSN, NCSN, \& Ramirez, M., MPH, PhD. (2019). Link for schools: A system to prevent trauma and its adverse impacts. Nasn School Nurse, 34(1), 21-24. doi:10.1177/1942602X18785010

Jefferson County Public Schools Envision Equity Score Card (2019). Retrieved from https://assessment.jefferson.kyschools.us/DMC/ee/eeDiscipline

Jensen, E. (2013). How poverty affects classroom engagement. Educational Leadership, 70(8), 24-30.

Johnson, M. (2018). The effects of traumatic experiences on academic relationships and expectations in justice-involved children. Psychology in the Schools, 55(3), 240249. doi:10.1002/pits. 22102

Keesler, J. M. (2014). A call for the integration of trauma-informed care among ntellectual and developmental disability organizations. Journal of Policy and Practice in Intellectual Disabilities, 11(1), 34-42.

Kelly, H. (2019). The School Safety and Resilence Act:A Summary. Kentucky Youth Advocates. Retrieved from https://kyyouth.org/the-school-safety-and-resiliency$\underline{\text { act/ }}$

Kenning, C. (2013). Kentucky kids top in trauma, mired in poverty, report says. The Courier-Journal. Retrieved from Retrieved from https://www.courierjournal.com/story/money/personal-finance/education/2013/11/04/kentucky-kidstops-in-trauma-mired-in-poverty-report-says/3436085/

Knight, C. (2019). Trauma informed practice and care: Implications for field instruction. Clinical Social Work Journal, 47(1), 79-89. doi:10.1007/s10615-0180661-x

Larson, S., Chapman, S., Spetz, J., \& Brindis, C. (2017). Chronic childhood trauma, mental health, academic achievement, and school-based health center mental health services. The Journal of School Health, 87(9), 675-686. doi:10.1111/josh. 12541

Listenbee, R. et al. (2012). Report of the Attorney General's National Task Force on Children Exposed to Violence. U.S. Department of Justice. Retrieved from http://www.justice.gov/defendingchildhood/cev-rpt-full.pdf. 
Lubit, R., \& Lubit, R. (2019). Why educators should care about social and emotional learning? New Directions for Teaching and Learning, 2019(160), 19-32. https://doi-org.echo.louisville.edu/10.1002/tl.20362

Mader, J. (2019, January 26). Can mental health training for teachers make a difference? The Hechinger Report. Retrieved from https://hechingerreport.org/californiaadopts-a-new-model-to-curb-preschool-suspensions/

Maul, A. (2018). Welcome Upswing of State and Federal Support for Trauma-Informed Practices and Policies. Center for Health Care Strategies, Inc. Retrieved from https://www.chcs.org/welcome-upswing-state-federal-support-trauma-informedpractices-policies/

McInerney, M., \& McKlindon, A. (2014). Unlocking the door to learning: Traumainformed classrooms \& transformational schools. 1-24.

McLaren, M. \& Krauth, O. (2020). JCPS, Bullitt, Oldham, archdiocese schools heed Beshear's call to close over coronavirus. Louisville Courier-Journal. Retrieved from https://www.courierjournal.com/story/news/education/2020/03/12/coronavirus-kentucky-gov-beshearcalls-k-12-schools-close/5021149002/

Mendelson, T., Tandon, S., O'Brennan, L., Leaf, P., \& Ialongo, N. (2015). Brief report: Moving prevention into schools: The impact of a trauma-informed school-based intervention. Journal of Adolescence, 43, 142-147. doi:10.1016/j.adolescence.2015.05.017

Merriam, S. B. (1998). Qualitative research and case study applications in education. San Francisco, CA: Jossey-Bass.

Miles, M. B., Huberman, A. M., \& Saldana, J. (2014). Qualitative data analysis: A method sourcebook. CA, US: Sage Publications.

Minero, E. (2017). When students are traumatized, teachers are too. Edutopia. Retrieved from https://www.edutopia.org/article/when-students-are-traumatized-teachers$\underline{\text { are-too }}$

Moon, J., Williford, A., \& Mendenhall, A. (2017). Educators' perceptions of youth mental health: Implications for training and the promotion of mental health services in schools. Children and Youth Services Review, 73, 384-391. doi:10.1016/j.childyouth.2017.01.006

National Child Traumatic Stress Network Schools Committee. (2008). Child Trauma Toolkit for Educators. National Center for Child Traumatic Stress, 1-21. 
NYSTeachs (2018). The trauma and learning policy initiative (TLPI). Retrieve from https://nysteachs.org/topic-resource/the-trauma-and-learning-policy-initiative-tlpi/

Oehlberg, B. (2008). Why schools needs to be trauma-informed. Trauma and Loss: Research and Interventions, 8(2), 1-4. Retrieve from http://www.traumainformedcareproject.org/resources/WhySchoolsNeedToBeTrau $\underline{\text { maInformed(2).pdf }}$

O'Grady, K. (2017, January/February 2017). Transforming Schools With TraumaInformed Care. ASCA School Counselor, 54(3), 9-13.

Osagiede, O., Costa, S., Spaulding, A., Rose, J., Allen, K., Rose, M., \& Apatu, E. (2018). Teachers' perceptions of student mental health: The role of school-based mental health services delivery model. Children \& Schools, 40(4), 240-248. doi:10.1093/cs/cdy020

Osher, D. (2018). Trauma and Learning Policy Initiative (TLPI): Trauma-sensitive schools descriptive study.

Overstreet, S., \& Chafouleas, S. (2016). Trauma-informed schools: Introduction to the special issue. School Mental Health : A Multidisciplinary Research and Practice Journal, 8(1), 1-6. doi:10.1007/s12310-016-9184-1

Perry, B. (2009). Examining child maltreatment through a neurodevelopmental lens: Clinical applications of the neurosequential model of therapeutics. Journal of Loss and Trauma, 14(4), 240-255.

Perry, B. L., \& Morris, E. W. (2014). Suspending Progress: Collateral Consequences of Exclusionary Punishment in Public Schools. American Sociological Review, 79(6), 1067-1087. https://doi.org/10.1177/0003122414556308

Perry, D., \& Daniels, M. (2016). Implementing trauma-informed practices in the school setting: A pilot study. School Mental Health: A Multidisciplinary Research and Practice Journal,8(1), 177-188. doi:10.1007/s12310-016-9182-3

Phifer, L. W., \& Hull, R (2016). Helping student heal: Observation of trauma-informed Practices in the schools. School Mental Health, 8(1), 201-205.doi: 10.1007/7s 12310-016-9183-2

Pletcher, B., O'Connor, M., Swift-Taylor, M., \& DallaPiazza, M. (2019). Adverse childhood experiences: A case-based workshop introducing medical students to trauma-informed care. Mededportal : The Journal of Teaching and Learning Resources, 15, 10803-10803. doi:10.15766/mep_2374-8265.10803 
Ridgard, T., Laracy, S., DuPaul, G., Shapiro, E., \& Power, T. (2015). Trauma-informed care in schools: A social justice imperative. Communique, 44(2), 14-15.

Rossen, E., Hull, R., \& Hull, R. V. (2013). Supporting and educating traumatized students: A guide for school based professionals: Oxford University Press.

Sacks, V., \& Murphey, D. (2018). The prevalence of adverse childhood experiences, nationally, by state, and by race or ethnicity-updated brief In: Child Trends. Retrieved from https://www. childtrends. org/publications ....

Sanders, J. R. “Case Study Methodology: A Critique.” In W.W. Welsh (ed.), Case Study Methodology in Educational Evaluation. Proceedings of the 1981 Minnesota Evaluation Conference. Minneapolis: Minnestoa Research and Evaluation Center, 1981.

Saldana, J. (2016) The Coding Manual for Qualitative Researchers. Thousand Oaks, CA:Sage

Soma, C., \& Allen, D. (2017). 10 Steps to create a trauma-informed school. Albion, MI.

Souers, K., \& Hall, P. (2016). Fostering resilient learners: Strategies for creating a trauma-sensitive classroom: ASCD.

Steinberg, A., Colasanti, K., Hückmann, D., \& Papazoglou, K. (2011). Echoes of 9/11 in the nyu classroom: A brief report from near ground zero. Traumatology, 17(3), 15-19. doi:10.1177/1534765610395618

Strauss, A.L. (1987) Qualitative analysis for socal scientist. Cambridge: Cambridge University Press.

Substance Abuse and Mental Health Services Administration (2014). SAMSHA's Concept of Trauma and Guidance for a Trauma-Informed Approach. HHS Publication No. (SMA) 14-4484. Rockville, MD: Substance Abuse and Mental Health Services Administration.

Thomas, M. S., Crosby, S., \& Vanderhaar, J. (2019). Trauma-informed practices in schools across two decades: an interdisciplinary review of research. Review of Research in Education, 43(1), 422-452. https://doiorg.echo.louisville.edu/10.3102/0091732X18821123

Tishelman, A.C., Haney, P., O’Brien, J.G., \& Blaustein, M.E. (2010). A framework for school-based psychological evaluations: Utilizing a "trauma lens." Journal of Child \& Adolescent Trauma, 3, 279-302. 
Torgerson, C. Love, H., \& Vennum, A. (2018). The buffering effect of belonging on the negative association of childhood trauma with adult mental health and risky alcohol use. Journal of Substance Abuse Treatment, 88, 44-50. doi: 10.1016/j.jsat.2018.02.00

Trauma Learning Policy Initiative https://traumasensitiveschools.org/about-tlpi/

van Manen, M. (1990). Research lived experience: Human science for an action sensitive pedagogy. Albany: State University of New York Press.

Voisin DR, Hunnicutt S, Neilands TB. (2011). Mechanisms linking violence exposure and school engagement among African American adolescents: examining the roles of psychological problem behaviors and gender. Am J Orthopsychiatry. 81(1):67-71.

Walkley, M., \& Cox, T. (2013). Building trauma-informed schools and communities. Children \& Schools, 35(2), 123-126. doi:10.1093/cs/cdt007

West, S., Day, A., Somers, C., \& Baroni, B. (2014). Student perspectives on how trauma experiences manifest in the classroom: Engaging court-involved youth in the development of a trauma-informed teaching curriculum. Children and Youth Services Review, 38, 58-65. doi:10.1016/j.childyouth.2014.01.013

Whitaker, R., Herman, A., Dearth-Wesley, T., Smith, H., Burnim, S., Myers, E., . . Kainz, K. (2019). Effect of a trauma-awareness course on teachers' perceptions of conflict with preschool-aged children from low-income urban households: A cluster randomized clinical trial. Jama Network Open, 2(4), 193193. doi:10.1001/jamanetworkopen.2019.3193

Wolpow, R., Johnson, M. M., Hertel, R., \& Kincaid, S. O. (2009). The heart of learning and teaching: Compassion, resiliency, and academic success. Olympia, WA: Washington State Office of Superintendent of Public Instruction Compassionate Schools.

Yin, R.K. (2009) Case study research: Design and methods. $\left(4^{\text {th }}\right.$ ed.). Thousand Oaks, CA: Sage.

Yin, R.K. (2014). Case study research: Design and methods. Thousand Oaks, CA: Sage. 
Appendix A - Trauma-Sensitive Checklist Survey Trauma-Sensitive School Checklist

\author{
Lealey Univernity \\ Center for Special Educaban
}

Trauma and Learning Policy Initiative

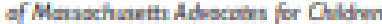

and the Legal Serrices Certer af Havard Low Schoel

The checklat as oreanined by five camporents imolved in madive a haumsannibive achool Each companent cansint of awend ninments.

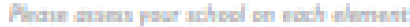
acranding to the following arak

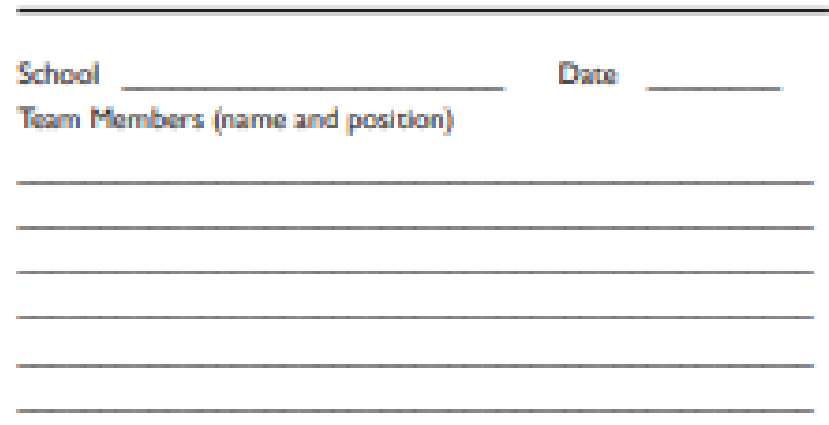

A trauma-sensitive school is a safe and respectful environment that enables students to build caring relationships with adults and peers, self-regulate their emotions and behaviors, and succeed academically, while supporting their physical health and well-being.

\title{
School-wide Policies and Practices
}

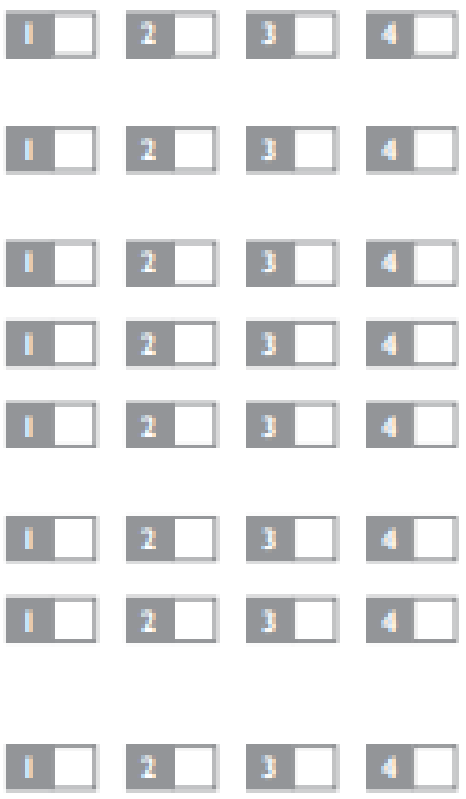

- Sthool containa proclictable and safe cmironmena fincluding charoom, halwapn, pleyground, and school bain) that are attentive to tramiticas and smenry mexds.

- Leadenhip (including principal and/es muperimendent) developa and implements a trauma-scruitive action plan, identifies harricrs to posgrem, and craluase mocen.

- General and special edacators conider the mole thut trauma may be plying in learning diffulties at achool

- Dincipline policia balanee accourtablity with an underatanding of trama.

- Support for ataff is available on a reguhar basis, induding uporvixion and/or conualtation with a trauma apert, clawrosm observatiom, and opportunities for tram work.

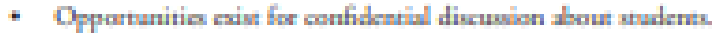

- School purticipate in safty planring, including enfurcament of court onders, tranaferring socondx safdy, notricting accos to student-record information, and wensitive handling of neports of wapected incidents of ahume or noglest.

- On-guing profenional devdlopment opportunitia occur as determined by staff noodh awomemerts.

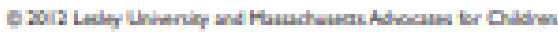




\section{Classroom Strategies and Techniques}
- Expectation are commuricasod in dear, conciac, and poxitive wavk, and grolls foe acthicvement of studemes affected by traumatic coperiences ane consiatent with the rat of the clan.

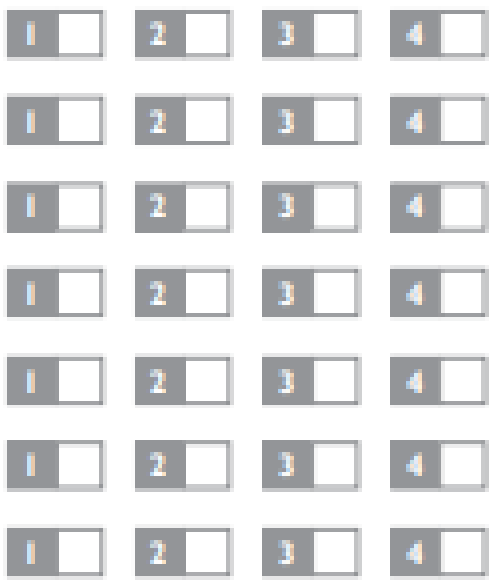
- Sradentx' atrengths and intencats ase cncouraged and incorporated.
- Activitio are arructured in predictable and cmotionally afe ways.
- Opportunitio cxist for atudents to learn and practice repulation of emotiom and modalation of bchavion.
- Claworoms employ poviàive mpports for behavior.
- Information à procmed and learning är aucucd waing maltiple modos.
- Opportanitio cxist for learning how so interact affectively with oshers.
- Opportanitio cxist for learning how as plan and follow through on axignents.

\section{Collaborations and Linkages with Mental Health}

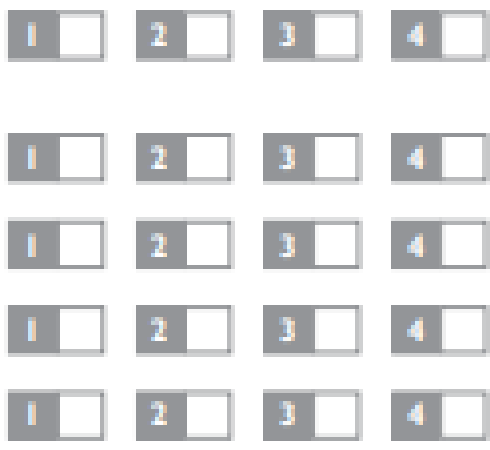

\section{Family Partnerships}

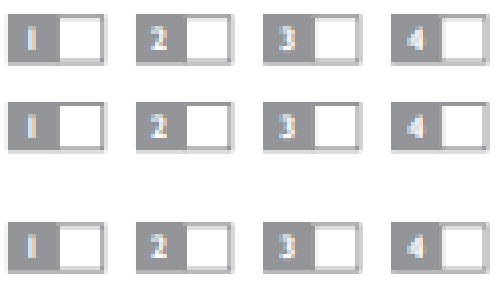

\section{Community Linkages}

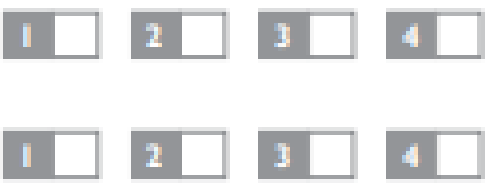

- Policio docaihe hew, when, and where to acfer familio for mental healh wapports; and staff activcly facilitate and follow through in upporting familia' access to tramu-crmpetent mental healh scrvices.

- Necra exints to trauma-ompetern servica for pevernion, carly intervention, tratment, and crain irservention.

- Pronocols exiat for helping studens tranaition hadk to shool frum other placcments

- Mental health services ane linguintically appoppriate and culturaly competent.

- Sraff has rgular opportunitia for awiatance from mental health providen in raponding apropriandy and confidentially to familin.

- Sraff uno a mepertnise of will to activdly engrege and bald poritive relationahipe with familics.

- Serategies to imodve parruts ane taloned to mext individual family neodh, and include fexihiling in selecting time and place for mectinga, araibbility of inserpreten, and ramalated materials.

- Mll commurications with and regarding families ropess the boands of confidentiliny.

- School devdops and maintains ungoing partmenhipe with state human scrvice aysoien and with community-basod agncies to facilituse access to sewasces.

- Whem powible, school and commanity agencies leverage funding to incacas the array of wapports available. 


\section{Appendix B - Proposed Timeline and Budget}

\begin{tabular}{|l|l|}
\hline Timeline & Proposed Budget \\
\hline $\begin{array}{l}\text { November 2018 - CITI Training } \\
\text { Complete }\end{array}$ & $\$ 0$ \\
\hline October 2019 - Submit Chapter 1 & $\$ 0$ \\
\hline December 2019 - Submit Chapter 3 & $\$ 0$ \\
\hline $\begin{array}{l}\text { January 2020 - Defend Dissertation } \\
\text { Proposal }\end{array}$ & $\$ 0$ \\
\hline $\begin{array}{l}\text { January 2020 - Apply for JCPS IRB } \\
\text { Approval }\end{array}$ & $\$ 0$ \\
\hline $\begin{array}{l}\text { January 2020 - Apply for UofL IRB } \\
\text { Approval }\end{array}$ & $\$ 0$ \\
\hline February 2020 - Conduct Interviews & $\$ 40$ Audio Recording Device \\
\hline $\begin{array}{l}* * \text { June 2020 - Conduct Interview - } \\
\text { moved due to COVID-19 }\end{array}$ & \\
\hline $\begin{array}{l}\text { April 2020 - Data Analysis and } \\
\text { Conclusion }\end{array}$ & $\$ 500$ Rev.com Transcription Service \\
\hline June 2020 - Submit Chapters 4 \& 5 & $\$ 0$ \\
\hline $\begin{array}{l}* * \text { August 2020 - Data Analysis } \\
\text { completed }\end{array}$ & $\$ 1100$ \\
\hline$* *$ October 2020 - Submit Chapters 4 \&5 & $\$ 0$ \\
\hline November 2020 - Defend Dissertation & $\$ 0$ \\
\hline December 2020 - Graduate & $\$ 0$ \\
\hline & Approximate Total \$ 540 \\
\hline Updated June 2020** & Grand Total \$1100 \\
\hline
\end{tabular}


Appendix C - Informed Consent

INFORMED CONSENT

TITLE OF RESEARCH STUDY:

THE MANY FACETS OF TRAUMA - HIGH NEED INDEX PRINCIPALS' PERSPECTIVES OF TRAUMA-INFORMED CARE

\section{Summary Information}

The purpose of this study is to examine high need index school principals' perceptions of trauma, how they address students experiencing trauma, and if, and how they utilize traumainformed care to remove barriers to trauma in high need index schools. The lived experiences of high need index principals will provide a wealth of information for principals to examine potential strategies to address student trauma within existing school-wide practices, policies, and procedures.

Participants in this study will be selected based on their Jefferson County Public School high need index scores above the 42\% based on 2018-19 school year percentages. After being identified, contacted, and agreeing to take part in the study, participants will sit down for a one-hour online interview and complete a five minute survey.

There are no foreseeable risks to this study other than possible discomfort in answering personal questions. Further protection of anonymity will be provided via pseudonym name and school name.

If you are interested in learning more about this study, please continue to read below.

\section{Introduction and Background Information}

You are invited to take part in a research study because your school score $42 \%$ or above on the Jefferson County Public School high need index score. The study is being conducted under the direction of Dr. Mary Brydon-Miller and Nicole Fields, M.Ed. at the University of Louisville.

\section{Purpose}

The purpose of this study is to examine high need index school principals' perceptions of trauma, how they address students experiencing trauma, and if, and how they utilize traumainformed care to remove barriers to trauma in high need index schools. The lived experiences of high need index principals will provide a wealth of information for principals to examine potential strategies to address student trauma within existing school-wide practices, policies, and procedures. 


\section{Procedures}

In this study, you will be asked to complete an online five minute trauma-sensitive checklist survey, and then answer questions in a one-hour interview via Microsoft Teams. You have been identified because your school's high need index score. The interview will ask you questions regarding your experience with trauma and trauma-informed care. A week prior to the interview, you will complete the trauma-sensitive checklist survey via survey monkey. Throughout the duration of the interview, you may decline to answer any questions that may make you uncomfortable. Your participation in the interview will last for one hour to conduct. The interview will be audio and video recorded, and will be transcribed verbatim.

Your interview transcripts will be shared with you if you choose to read them. Results of the overall research study will be shared with you at your request. Your interview will not be stored and shared for future research even if identifiable private information, such as your name and medical record number, are removed.

\section{Potential Risks}

There are no foreseeable risks other than possible discomfort in answering personal questions. There may also be unforeseen risks.

\section{Benefits}

You may not benefit personally by participating in this study. The information collected may not benefit you directly; however, the information may be helpful to others.

\section{Alternatives}

Instead of taking part in this study, you could choose to recommend a fellow principal colleague to the interviewer to take part, or you can simply decline to take part.

\section{Payment}

You will not be paid for your time, inconvenience, or expenses while you are in this study.

\section{Confidentiality}

Total privacy cannot be guaranteed. We will protect your privacy to the extent permitted by law. If the results from this study are published, your name will not be made public. Once your information leaves our institution, we cannot promise that others will keep it private.

Your information may be shared with the following:

- Organizations that provide funding at any time for the conduct of the research.

- The University of Louisville Institutional Review Board, Human Subjects Protection Program Office, Privacy Office, others involved in research administration and research and legal compliance at the University, and others contracted by the University for ensuring human participants safety or research and legal compliance

- The local research team

- People who are responsible for research, compliance and HIPAA/privacy oversight at the institutions where the research is 
conducted

- Applicable government agencies, such as:

- Office for Human Research Protections

\section{Security}

The data collected about you will be kept private and secure by being located on a password protected computer.

\section{Voluntary Participation}

Taking part in this study is completely voluntary. You may choose not to take part at all. If you decide not to be in this study, you won't be penalized or lose any benefits for which you qualify. If you decide to be in this study, you may change your mind and stop taking part at any time. If you decide to stop taking part, you won't be penalized or lose any benefits for which you qualify. You will be told about any new information learned during the study that could affect your decision to continue in the study.

\section{Research Participant's Rights}

If you have any questions about your rights as a research participant, you may call the Human Subjects Protection Program Office at (502) 852-5188. You may discuss any questions about your rights as a research participant, in private, with a member of the Institutional Review Board (IRB). You may also call this number if you have other questions about the research, and you cannot reach the study doctor, or want to talk to someone else. The IRB is an independent committee made up of people from the University community, staff of the institutions, as well as people from the community not connected with these institutions. The IRB has approved the participation of human participants in this research study.

\section{Questions, Concerns and Complaints}

If you have any questions about the research study, please contact Dr. Mary Brydon-Miller at 502-852- 6887.

If you have concerns or complaints about the research or research staff and you do not wish to give your name, you may call the toll free number 1-877-852-1167. This is a 24 hour hot line answered by people who do not work at the University of Louisville.

\section{Acknowledgment}

This document tells you what will happen during the study if you choose to take part. By answering questions on the initial online survey, you indicate that this study has been explained to you, that your questions have been answered, and that you agree to take part in the study. You are not giving any legal rights to which you are entitled by enrolling in this study. You can retain a copy of this consent form for your records. 
Phone number for participants to call for questions: 502-852-6887

Investigator(s) name, degree, phone number, University

Department, \& address: Mary Brydon-Miller, Ph.D.

Professor, Educational Leadership, Evaluation, and Organizational

Development ELOD Ph.D. Program Director

College of Education and

Human Development

University of Louisville

Louisville, KY 40292

Site(s) where study is to be conducted: various schools in Jefferson County Public Schools 


\section{Appendix D - Informed Protocol - Principals}

Thank you for the opportunity to meet and learn more about your experience with trauma and traumainformed care. This interview will be video recorded via Microsoft Team and audio recorded to ensure your words are recorded accurately. Please review and sign the informed consent to acknowledge your agreement to participate in this study. A pseudonym will be assigned to identify you and your school for confidentiality purposes. No potential risk or harm will come to you as a participant.

During the interview I will be asking you some questions about your experiences and understanding in regards of trauma and trauma-informed care. This interview should be completed between 45-60 minutes to complete. Your experiences and opinion are valued.

\begin{tabular}{|c|c|c|}
\hline Guiding Interview Questions & Alignment to Research & Alignment to Flexible \\
\hline $\begin{array}{l}\text { 1. How do you define trauma? } \\
\text { a. What are the signs of trauma? } \\
\text { b. What kinds of trauma have } \\
\text { c. your students experienced? } \\
\text { have you faced when working } \\
\text { with students who have } \\
\text { experienced trauma? }\end{array}$ & RQ:1 & Infrastructure and leadership \\
\hline $\begin{array}{l}\text { 2. How do you define trauma- } \\
\text { informed care? } \\
\text { a. What obstacles or barriers have } \\
\text { you faced when trying to } \\
\text { implement trauma-informed care } \\
\text { within your building? }\end{array}$ & RQ: 1 & Infrastructure and leadership \\
\hline $\begin{array}{l}\text { 3. What do you believe is the } \\
\text { principals' responsibility when } \\
\text { addressing trauma within their } \\
\text { school buildings? } \\
\text { a. What policies, if any, does } \\
\text { your school have which } \\
\text { recognizes and addresses } \\
\text { trauma within your school } \\
\text { building? } \\
\text { b. What procedures, if any, does } \\
\text { your school have which } \\
\text { recognizes and addresses } \\
\text { trauma with your school } \\
\text { building? } \\
\text { c. What practices, if any, do you } \\
\text { as the school principal, } \\
\text { implement to address students } \\
\text { experiencing trauma? }\end{array}$ & RQ: 1,2 & $\begin{array}{l}\text { Infrastructure and leadership; } \\
\text { policies, procedures, and } \\
\text { protocols; nonacademic strategies }\end{array}$ \\
\hline $\begin{array}{l}\text { 4. Within in your current school-wide } \\
\text { practices how is trauma addressed } \\
\text { academically? } \\
\text { a. What practices are implemented } \\
\text { specifically in the classroom } \\
\text { regarding trauma academically? } \\
\text { b. What is the most difficult part } \\
\text { when addressing trauma in regards } \\
\text { to academics? } \\
\text { c. What is the easiest part when } \\
\text { addressing trauma in regards to } \\
\text { academics? }\end{array}$ & RQ: 2,3 & $\begin{array}{l}\text { Classroom-based academic } \\
\text { strategies; Infrastructure and } \\
\text { leadership; Role of mental health } \\
\text { (internal and external); Policies, } \\
\text { procedures, and protocols }\end{array}$ \\
\hline
\end{tabular}




\begin{tabular}{|c|c|c|c|}
\hline 5. & $\begin{array}{l}\text { Within in your current school-wide } \\
\text { practice how is trauma addressed } \\
\text { behaviorally? } \\
\text { What practices are implemented } \\
\text { specifically in the classroom } \\
\text { regarding trauma and behavior? } \\
\text { What is the most difficult part } \\
\text { when addressing trauma in regard } \\
\text { to behavior? } \\
\text { What is the easiest part when } \\
\text { addressing trauma in regards to } \\
\text { behavior? }\end{array}$ & RQ: 2,3 & $\begin{array}{l}\text { Nonacademic strategies; } \\
\text { Infrastructure and leadership; } \\
\text { Role of mental health (internal } \\
\text { and external); Policies, } \\
\text { procedures, and protocols }\end{array}$ \\
\hline 6. & $\begin{array}{l}\text { How are strategies communicated } \\
\text { to stakeholders (teachers, parents, } \\
\text { students, etc.) on how trauma is } \\
\text { within your school? }\end{array}$ & RQ: $1,2,3$ & $\begin{array}{l}\text { Infrastructure and leadership; } \\
\text { Policies, procedures, and } \\
\text { protocols }\end{array}$ \\
\hline 7. & $\begin{array}{l}\text { What kind of training or } \\
\text { professional development have } \\
\text { specifically regarding trauma and } \\
\text { trauma-informed care? } \\
\text { How efficient or not was the } \\
\text { trauma training? } \\
\text { What additional or supports would } \\
\text { be beneficial to you regarding } \\
\text { trauma and trauma-informed care? }\end{array}$ & RQ: 2,3 & Professional Development \\
\hline 8. & $\begin{array}{l}\text { What supports have you receive } \\
\text { from the district/central office } \\
\text { provided you and your school } \\
\text { regarding trauma and trauma- } \\
\text { informed care? } \\
\text { What was the most important } \\
\text { resource provided or not provided? }\end{array}$ & RQ: 2,3 & $\begin{array}{l}\text { Role of mental health (internal } \\
\text { and external) }\end{array}$ \\
\hline 9. & $\begin{array}{l}\text { What are you perceptions on the } \\
\text { whether the trauma-informed } \\
\text { practices implemented in your } \\
\text { building achieve their intended } \\
\text { purposes? } \\
\text { What do you recommend for } \\
\text { future practices? }\end{array}$ & RQ: 3 & $\begin{array}{l}\text { Professional Development; } \\
\text { Infrastructure and leadership; } \\
\text { Policies, procedures, and } \\
\text { protocols }\end{array}$ \\
\hline
\end{tabular}




\section{Appendix E - Interview Protocol - Social-Emotional Director}

Thank you for the opportunity to meet and learn more about your experience with trauma and traumainformed care. This interview will be video and audio recorded to ensure your words are recorded accurately. Please review and sign the informed consent to acknowledge your agreement to participate in this study. A pseudonym will be assigned to identify you and your school for confidentiality purposes. No potential risk or harm will come to you as a participant.

During the interview I will be asking you some questions about your experiences and understanding in regards of trauma and trauma-informed care. This interview should be completed between 45-60 minutes to complete. Your experiences and opinion are valued.

\begin{tabular}{|c|c|c|}
\hline Guiding Interview Questions & Alignment to Research Questions & Alignment to Flexible Framework \\
\hline $\begin{array}{l}\text { 1. How do you define trauma? } \\
\text { a. What are the signs of trauma? } \\
\text { b. What kinds of trauma have your } \\
\text { students experienced? } \\
\text { c. What obstacles or barriers have } \\
\text { you faced when working with } \\
\text { students who have experienced } \\
\text { trauma? }\end{array}$ & RQ:1 & Infrastructure and leadership \\
\hline $\begin{array}{l}\text { 2. How do you define trauma-informed } \\
\text { care? } \\
\text { a. What obstacles or barriers have you } \\
\text { faced when trying to implement } \\
\text { trauma-informed care within the } \\
\text { district? }\end{array}$ & RQ: 1 & Infrastructure and leadership \\
\hline $\begin{array}{l}\text { 3. What do you believe is the } \\
\text { districts/central office responsibility } \\
\text { when addressing trauma within the } \\
\text { school district? } \\
\text { a. What do you believe is the } \\
\text { district/central office } \\
\text { responsibility when addressing } \\
\text { trauma within the schools? } \\
\text { b. What policies, if any, does the } \\
\text { district have which recognizes } \\
\text { and addresses trauma within } \\
\text { your school district? } \\
\text { c. What procedures, if any, does } \\
\text { the district have which } \\
\text { recognizes and addresses trauma } \\
\text { with the school district? } \\
\text { d. What practices, if any, does the } \\
\text { district have to address students } \\
\text { experiencing trauma? }\end{array}$ & RQ: 1,2 & $\begin{array}{c}\text { Infrastructure and leadership; } \\
\text { policies, procedures, and protocols; } \\
\text { nonacademic strategies }\end{array}$ \\
\hline $\begin{array}{l}\text { 4. How does the district address trauma } \\
\text { in regards to academics? } \\
\text { a. What practices are implemented } \\
\text { specifically in the district regarding } \\
\text { trauma academically? } \\
\text { b. What is the most difficult part when } \\
\text { addressing trauma in regards to } \\
\text { academics? } \\
\text { c. What is the easiest part when } \\
\text { addressing trauma in regards to } \\
\text { academics? }\end{array}$ & RQ: 2,3 & $\begin{array}{l}\text { Classroom-based academic } \\
\text { strategies; Infrastructure and } \\
\text { leadership; Role of mental health } \\
\text { (internal and external); Policies, } \\
\text { procedures, and protocols }\end{array}$ \\
\hline
\end{tabular}




\begin{tabular}{|c|c|c|c|}
\hline $\begin{array}{l}5 . \\
\text { a. } \\
\text { b. }\end{array}$ & $\begin{array}{l}\text { How does the district address trauma } \\
\text { in regards to behavior? } \\
\text { What practices are implemented } \\
\text { specifically in the district regarding } \\
\text { trauma and behavior? } \\
\text { What is the most difficult part when } \\
\text { addressing trauma in regard to } \\
\text { behavior? } \\
\text { What is the easiest part when } \\
\text { addressing trauma in regards to } \\
\text { behavior? }\end{array}$ & RQ: 2,3 & $\begin{array}{l}\text { Nonacademic strategies; } \\
\text { Infrastructure and leadership; Role } \\
\text { of mental health (internal and } \\
\text { external); Policies, procedures, and } \\
\text { protocols }\end{array}$ \\
\hline & $\begin{array}{l}\text { How are strategies communicated to } \\
\text { stakeholders (principals, teachers, } \\
\text { parents, students, etc.) on how trauma } \\
\text { is within the district? }\end{array}$ & RQ: $1,2,3$ & $\begin{array}{l}\text { Infrastructure and leadership; } \\
\text { Policies, procedures, and protocols }\end{array}$ \\
\hline a. & $\begin{array}{l}\text { What kind of training or professional } \\
\text { development has the district offered } \\
\text { to specifically trauma and trauma- } \\
\text { informed care? } \\
\text { How are schools selected to } \\
\text { participate in the training? } \\
\text { How efficient or not was the trauma } \\
\text { training? } \\
\text { What additional or supports would be } \\
\text { beneficial to schools regarding } \\
\text { trauma and trauma-informed care? }\end{array}$ & RQ: 2,3 & Professional Development \\
\hline 8. & $\begin{array}{l}\text { What are you perceptions on the } \\
\text { whether the trauma-informed } \\
\text { practices implemented in the district } \\
\text { have achieve their intended purposes? } \\
\text { What do you recommend for future } \\
\text { practices? }\end{array}$ & RQ: 3 & $\begin{array}{c}\text { Professional Development; } \\
\text { Infrastructure and leadership; } \\
\text { Policies, procedures, and protocols }\end{array}$ \\
\hline
\end{tabular}




\section{Appendix F - Recruitment Email}

Mary Brydon-Miller, Ph.D, Principal Investigator

Nicole Fields, M.Ed, Co-Investigator

University of Louisville, Room 314

College of Education

1905 South $1^{\text {st }}$ Street

Louisville, KY 40208

Dear Building Principal,

We are writing to see if you would like to participate in a new research study being conducted by Dr.

Brydon-Miller and I at the University of Louisville. The purpose of my study is to examine high need index school principals' perceptions of trauma, how they address students experiencing trauma, and if, and how they utilize trauma-informed care to remove barriers to trauma in high need index schools. The lived experience of high need index principals will provide a wealth of information for principals to examine potential strategies to address student trauma within existing school-wide practices, policies, and procedures.

Participants in this study will be selected based on their Jefferson County Public School high need index scores above the $42 \%$ based on 2018-19 school year percentages. After being identified, contacted, and agreeing to take part in the study, participants will sit down for a one-hour online interview and complete a five minute survey. You may not benefit personally by participating in this study. The information collected may not benefit you directly; however, the information may be helpful to others.

During the interview I will be asking you some questions about your experiences and understanding in regards of trauma and trauma-informed care. This interview should be completed between 45-60 minutes to complete. Your experiences and opinion are valued. This interview will be video recorded via Microsoft Team and audio recorded to ensure your words are recorded accurately. The interview will be conducted at a time convenient for you. A pseudonym will be assigned to identify you and your school for confidentiality purposes.

If you have any questions about the research study, please contact Dr. Mary Brydon-Miller at 502-852-6887. If you have concerns or complaints about the research or research staff and you do not wish to give your name, you may call the toll free number 1-877-852-1167. This is a 24 hour hot line answered by people who do not work at the University of Louisville.

If you would like to partake in this research, please review and sign the informed consent to acknowledge your agreement to participate in this study.

Sincerely,

Mary Brydon-Miller, Ph.D, Principal Investigator

Nicole Fields, M.Ed, Co-Investigator 
Education

\section{CURRICULUM VITAE \\ Nicole Fields \\ Nicole.Fields@jefferson.kyschools.us}

2020 Ed.D: Education Leadership \& Organizational Development

University of Louisville - Louisville, KY

2014 Master of Arts - School Guidance Counseling

Spalding University - Louisville, KY

2010 Master of Arts - Human Resources Development

Webster University - St. Louis, MO

2004 Bachelors of Science in Sociology

University of Louisville - Louisville, KY

Professional Experience

2020

Professional School Counselor

2018 - 2019 Professional School Counselor

- Iroquois High School

Jefferson County Public School - Marion C. Moore School

2015 - 2018 Professional School Counselor

2010 - 2015 Family Resource Center Coordinator

Jefferson County Public School - Greenwood Elementary School

Jefferson County Public School - Laukhuf and Wilt Elementary School

2008 - 2010 Outreach Director

$2006-2008$ U.S. Trainer

Girl Scouts of Kentuckiana

2005 - 2006 Formal Rater/IBM Lenovo Strategic Account Specialist

UPS Custom Brokerage

2003 - 2005 Metropolitan College Representative

UPS Worldport

National Presentation and Contributions

Presented at University Council for Educational Administration Graduate Student

Summit, 2018 Houston, TX Roundtable - School-Based Mental Health Programs'

Impact on Mental Health Disparities \& Trauma-Informed Care

Presented at University of Louisville - Black Family Conference, 2018 Louisville, KY

Session - Parent Communication with Schools

Presented at Finding Your Purpose and Claiming Victory in Your Storm, 2019

Session - Surviving Trauma - Louisville, KY

Presented at University Council for Educational Administration Graduate Student

Summit, 2019 New Orleans, LA Paper Session - Trauma-Informed Care:

School Administrators \& Student Support Team Beliefs and Understandings

Presented at University Council for Educational Administration Graduate Student

Summitt, 2020 Virtual - Ignite Sessions - Principal Perceptions on Trauma - Student

Trauma, Pandemic Effects, and Racial Unrest 